\title{
Effects of Particle Composition on Thorium Scavenging in the North Atlantic
}

3

4

5

\author{
Paul Lerner*a, Olivier Marchal ${ }^{\mathrm{a}}$, Phoebe J. Lam ${ }^{\mathrm{b}}$, and Andrew Solow ${ }^{\mathrm{a}}$

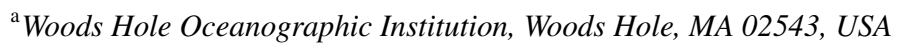 \\ ${ }^{\mathrm{b}}$ University of California Santa Cruz, Santa Cruz, CA 95064, USA
}

${ }^{*}$ Corresponding Author. Address: Department of Marine Chemistry and Geochemistry, Woods Hole Oceanographic Institution, 266 Woods Hole Road, Clark 448 (MS\#25), Woods Hole, MA (Tel:1-508-289-3278)

email address: plerner@whoi.edu 


\begin{abstract}
The dependence of thorium scavenging by particles on particle composition is examined at selected stations of the U.S. GEOTRACES North Atlantic Section (GA03). Scavenging is here described by the apparent, first-order rate constant of Th adsorption onto particles $\left(k_{1}\right)$, as estimated from an inversion of Th radioisotope and radioactive parent data. Our $k_{1}$ estimates are regressed against particle phase data using two different models. Model I considers biogenic particles (POC+PIC+bSi), lithogenic particles, Mn (oxyhydr)oxides, and Fe (oxyhydr)oxides as regressors, and $k_{1}$ as the regressand. Model II considers $\ln (\mathrm{POC}+\mathrm{PIC}+\mathrm{bSi}), \ln ($ lithogenic particles), $\ln \left(\mathrm{Mn}\right.$ (oxyhydr)oxides), and $\ln \left(\mathrm{Fe}\right.$ (oxyhydr)oxides) as regressors, and $\ln \left(k_{1}\right)$ as the regressand, where $\ln ()$ denotes the natural logarithm. Thus, models I and II posit that the effects of particle phases on $k_{1}$ are, respectively, additive and multiplicative. These models are applied to three groups of stations: (i) all selected stations, (ii) stations west of the Mauritanian upwelling region ("western stations"), and (iii) stations within that region ("eastern stations").

We find that model II appears to better describe the effect of particle composition on $k_{1}$ than model I. Particle composition explains a larger fraction of the variance of $k_{1}$ for the eastern stations ( $R^{2}=0.60$ for model I and 0.67 for model II) than for the western stations $\left(R^{2}=0.26\right.$ for model I and 0.39 for model II). When considering all stations, the variance of $k_{1}$ explained by particle composition is intermediate $\left(R^{2}=0.50\right.$ for model I and 0.51 for model II). According to model II, the variance of $k_{1}$ explained by particle composition is predominantly due to biogenic particles at the eastern stations and to Mn (oxyhydr)oxides at the western stations. Additionally, we find that particle composition does not explain a significantly different proportion of variance of $k_{1}$ than particle concentration. It is thus concluded that, at our selected stations, (i) biogenic particles and Mn (oxyhydr)oxides more strongly influence Th scavenging than any other phases considered, and (ii) particle composition and particle concentration have comparable effects on this process.
\end{abstract}

\title{
1 Introduction
}

The high particle reactivity of radioactive thorium isotopes in seawater has resulted in their widespread use in evaluating processes affecting marine particles. Examples include the use of ${ }^{234} \mathrm{Th}$ to estimate the export of particulate matter from the surface ocean (Bhat et al., 1969; 
Coale and Bruland, 1987; Buesseler et al., 1992, 2006), and the applications of ${ }^{230}$ Th to paleooceanography, including for estimating past changes in sediment redistribution (François et al., 2004). However, the use of thorium isotopes to investigate these processes depends partly on our understanding of how the metal attaches to particles. In seawater, thorium exists in the +IV oxidation state (Choppin and Wong, 1998) and has a strong binding affinity to oxygen containing compounds (Santschi et al., 2006). Thus, one may expect the affinity of thorium for particles to depend on their chemical composition and surface charge.

Previous studies have examined the dependence of Th scavenging on particle composition. Balistrieri et al. (1981) found that stability constants for the adsorption of thorium onto particles in the deep subtropical North Atlantic were closer in magnitude to those for the adsorption of Th onto organic compounds than to those for metal oxides. Using sediment trap data from a variety of regions including the Equatorial Pacific, the Southern Ocean, and the North Atlantic, Chase et al. (2002) explored the relationship between the partition coefficient for ${ }^{230} \mathrm{Th}, K_{D}$, and particle composition (in their study, $K_{D}$ was defined as $A_{p *} / A_{d}$, where $A_{p *}$ is the ${ }^{230} \mathrm{Th}$ activity per gram of particles in the sediment trap, and $A_{d}$ is the ${ }^{230} \mathrm{Th}$ activity per gram of seawater $1000 \mathrm{~m}$ above the trap). They found that $K_{D}$ is positively correlated with $\mathrm{CaCO}_{3}$ weight fraction $\left(\% \mathrm{CaCO}_{3}\right)\left(r^{2}=\right.$ $0.66)$, weakly and positively correlated $\%$ lithogenic material $\left(r^{2}=0.15\right)$, negatively correlated with \% biogenic silica $\left(r^{2}=0.59\right)$, and not significantly correlated with $\%$ particulate organic matter. Using the data of Chase et al. (2002) from the North Atlantic, Equatorial Pacific, and Southern Ocean, together with data from the Arabian Sea, Scholten et al. (2005) reported that $K_{D}$ exhibits significant positive correlation with $\% \mathrm{CaCO}_{3}\left(r^{2}=0.37\right), \%$ particulate organic carbon $\left(r^{2}=0.11\right)$, and \% lithogenic material $\left(r^{2}=0.34\right)$, and a significant negative correlation with \% biogenic silica $\left(r^{2}=0.40\right)$. However, each of these correlations were only significant when including data from the Southern Ocean; upon removing this dataset, only a weak, negative relationship between $K_{D}$ and \% biogenic silica was apparent $\left(r^{2}=0.08\right)$ (Scholten et al., 2005). Further restricting the analysis to datasets from the North Atlantic, including the Middle Atlantic Bight (Biscaye et al., 1988), the Sargasso Sea (Anderson et al., 1983), and stations near the Canary 
Islands (Scholten et al., 2001), $K_{D}$ shows a significant, but weak, negative relationship with \% $\mathrm{CaCO}_{3}\left(r^{2}=0.05\right)$, positive relationship with \% lithogenic material $\left(r^{2}=0.11\right)$, and no significant relationship with $\%$ particulate organic carbon and \% biogenic silica (Figure $\mathrm{S} 1 ; K_{D}$ and particle composition data from Chase et al. (2002)).

Roy-Barman et al. (2005) found that the relationship between the fraction of thorium present in particles and the particle composition varies between Th isotopes. From ${ }^{230,234}$ Th data collected by sediment traps deployed in the Northeast Atlantic, they found particulate ${ }^{230} \mathrm{Th}$ (in units of dpm/gram of particles) to show the strongest (positive) correlation with lithogenic material and particulate Mn, whereas particulate ${ }^{234} \mathrm{Th}$ (dpm/gram of particles) showed the strongest (positive) correlation with particulate organic carbon. They also found biogenic opal to have little or no correlation with either particulate ${ }^{230} \mathrm{Th}$ or ${ }^{234} \mathrm{Th}$. From sediment traps deployed from 2000 to 2003 as part of the Oceanic Flux Program off Bermuda (at 500, 1500, and 3200 m), Roberts et al. (2009) reported only a significant positive relationship between $K_{D}$ and \% total carbohydrate content of particles. However, from data collected from the same program between 2005 and 2007, Chuang et al. (2013) found the strongest positive relationship between $K_{D}$ and $\% \mathrm{CaCO}_{3}$, although they speculated that such a relationship was caused by the coating of this mineral phase by various biopolymers.

The recent radionuclide and particle concentration dataset obtained along the U.S. GEOTRACES North Atlantic transect (GA03) provides a unique opportunity to study the dependence of Th scavenging on particle composition in oceanic waters. Lam et al. (2015) have reported measurements of small $(0.8-51 \mu \mathrm{m})$ and large $(\geq 51 \mu \mathrm{m})$ bulk particle concentrations as well as particle phase concentrations, including particulate organic carbon (POC), particulate inorganic carbon (PIC), biogenic opal (bSi), lithogenic material, and manganese and iron (oxyhydr)oxides, obtained along GA03. Hayes et al. (2015a) have used the ${ }^{230}$ Th (Hayes et al., 2015b) and particle (Lam et al., 2015) data from GA03 to determine how particle composition affects the partitioning of Th between particulate and dissolved phases. They estimated the distribution coefficient for ${ }^{230} \mathrm{Th}$ from $K_{D}=A_{p} /\left(A_{d} P\right)$, where $A_{p}$ is the ${ }^{230} \mathrm{Th}$ activity in the particulate phase $\left(\mathrm{dpm} / \mathrm{m}^{3}\right), A_{d}$ is the 
${ }^{230} \mathrm{Th}$ activity in the dissolved phase $\left(\mathrm{dpm} / \mathrm{m}^{3}\right)$, and $P$ is bulk particle concentration $(\mu \mathrm{g} / \mathrm{kg})$. They found that $K_{D}$ is largest for Mn and Fe (oxyhydr)oxides (116.8 g/g and $32.8 \mathrm{~g} / \mathrm{g}$, respectively), and smallest for particulate organic matter $(0.3 \mathrm{~g} / \mathrm{g})$. They could not derive significant values of $K_{D}$ for opal, consistent with a similar result obtained for trap particles (Roy-Barman et al., 2005).

Importantly, most of pre-existing studies focused on the effects of particle composition on the partitioning of thorium between the dissolved and particulate phases, rather than on the kinetics of sorption reactions. Below the euphotic zone, thorium is generally thought to undergo a reversible exchange with slowly sinking particles (Nozaki et al., 1981; Bacon and Anderson, 1982). In this model, thorium cycling is governed by three parameters: the rate constant of Th adsorption onto particles $\left(k_{1}\right)$, the rate constant of Th desorption from particles $\left(k_{-1}\right)$, and the particle sinking speed (w). A more complete treatment includes in addition the rate constant of Th release from particles during particle degradation ( $\beta_{-1}$; Clegg et al. (1991a)). The quantities $k_{1}, k_{-1}$, and $\beta_{-1}$ should be viewed as apparent, first-order rate constants given the various assumptions in the model, such as the consideration of only one particle class. Under a set of assumptions, including steady state, three of these rate parameters are related to $K_{D}$ by the expression $K_{D}=k_{1} /\left(\left(k_{-1}+\beta_{-1}\right) P\right)$ (Honeyman et al., 1988; Lerner et al., 2017). Thus, the processes of thorium adsorption, thorium desorption, and particle degradation may each influence the observed partitioning of the metal between the dissolved and particulate forms.

Several studies have investigated the effects of particle concentration on estimates of $k_{1}$ in oceanic waters. Bacon and Anderson (1982) found a linear relationship between $k_{1}$ and $P$ from samples taken from the Guatemala and Panama Basins. Honeyman et al. (1988) proposed that $k_{1}$ could be related to particle concentration as $k_{1}=k_{1, c} P^{b}$, where $k_{1, c}$ and $b$ are positive constants. If $b<1$, then $K_{D}$ would decrease with increasing particle concentration (assuming invariant $k_{-1}$ and $\left.\beta_{-1}\right)$, the so-called "particle concentration effect" (Honeyman and Santschi, 1989). In this case, the thorium activity in filterable particles would be controlled by colloidal coagulation. In contrast, if $b=1$, the influence of colloids on Th partitioning between the solution and filterable particles would be absent (Honeyman et al., 1988). Numerous model studies have relied on this relationship 
between $k_{1}$ and $P$, generally assuming $b=1$ (Clegg and Sarmiento, 1989; Clegg et al., 1991b; Clegg and Whitfield, 1993; Burd et al., 2000). In recent work, Lerner et al. (2017) estimated the vertical distribution of $k_{1}$ at selected stations of GA03 from an inversion of Th radioisotope, Th radioactive parent, and bulk particle concentration data. They found that $k_{1}$ appears to be proportional to $P^{b}$ with $b \geq 1$, suggesting that colloidal coagulation due to Brownian pumping (Honeyman et al., 1988) does not noticeably affect on Th removal at these stations. On the other hand, to our knowledge, no previous studies have considered the relationship between $k_{1}$ and particle composition in oceanic waters.

The objective of this paper is to examine the influence of particle composition on the rate constant of Th adsorption $\left(k_{1}\right)$ onto particles obtained along the GA03 transect in the North Atlantic. We consider two distinct regression models to describe this influence: in a first model, the effects of different particle types on $k_{1}$ are additive, whereas in a second model they are multiplicative. We examine the influence of particle composition on $k_{1}$ for three groups of stations: (i) stations both west and east of the Mauritanian upwelling region, (ii) stations west of the Mauritanian upwelling region, and (iii) stations within the Mauritanian upwelling region. The effect of particle composition on $k_{1}$ is contrasted with that of particle concentration in order to determine whether it is the chemical nature of the particles or the number of surface sites available for adsorption which dominates the specific rate at which Th is removed from solution. Our study therefore complements previous works on the effect of particle composition on thorium scavenging by identifying the particle phases that appear to govern the kinetics of Th adsorption onto particles.

This paper is organized as follows. The particle and radiochemical data considered in this study are summarized, and the estimates of $k_{1}$ obtained by data inversion are presented in section 2. Results from the regression analyses are contained within section 3. In section 4 , we determine the relative importance of different particulate phases to the explained variance in $k_{1}$, attempt to interpret our results kinetically, clarify the paleoceanographic implications of our study, discuss the influence of observational errors, and contrast the effects of particle composition and particle concentration on our $k_{1}$ estimates. Conclusions follow in section 5 . 


\section{Methods}

\subsection{Particle and Radiochemical Data}

We use data collected aboard the R/V Knorr along the GA03 transect in October 2010 (leg GT10) and November-December 2011 (leg GT11; red stars in Figure 1). The first leg (GT10) of the transect went from Lisbon to Cape Verde, while the second leg (GT11) ran from Woods Hole to Cape Verde. We consider only the eleven stations highlighted in red (Fig. 1). At these stations (referred to below as the "selected" stations), the impact of lateral and vertical transport on thorium isotope and particle budgets appear to be small compared to the impact of sorption reactions and particle processes (Lerner et al., 2017). In addition, we rely only on data collected at depths located outside nepheloid layers, where processes not considered in this study presumably take place. Station GT11-16 near the TAG hydrothermal vent is also excluded from the present analysis because of the very high concentrations of Fe (oxyhydr)oxides measured at that station (Lam et al., 2015).

Particle phase concentrations considered in this work are the sum of the "small" and "large" size classes. Particles in the small $(1-51 \mu \mathrm{m})$ and large $(>51 \mu \mathrm{m})$ size fractions were sampled using a WTS-LV McLane pump modified to include dual flow paths and equipped with 142-mm "miniMULVFS" filter holders (Bishop et al., 2012). One filter holder was loaded with a 51- $\mu$ m Sefar polyester mesh prefilter followed by paired Whatman QMA quartz fiber filters $(1-\mu \mathrm{m}$ nominal pore size). The other filter was loaded with another $51-\mu \mathrm{m}$ polyester prefilter followed by paired $0.8-\mu \mathrm{m}$ Pall Supor800 polyethersulfone filters. Further details about the method of particle collection can be found in Lam et al. (2015).

The bulk chemical composition of the collected particles was determined as follows (notice that particle composition data used in this study are all in units of $\mathrm{mg}$ per $\mathrm{m}^{3}$ of seawater). For PIC, subsamples were taken from the QMA filters for analysis in the small size fraction, while subsamples were taken from the polyester prefilters for analysis in the large size fraction. PIC was measured using coulometry or salt-corrected [Ca]. Total particulate carbon in the small (large) size fraction was analyzed from subsamples taken from QMA filters (polyesther prefilters) and 
was measured using a Dynamic Flash Combustion technique. POC was taken as the difference between total particulate carbon and particulate inorganic carbon.

Biogenic silica in the small and large size fractions were measured from subsamples taken from the Supor and polyester prefilters, respectively. Silica (in $\mathrm{mol} / \mathrm{m}^{3}$ ) was determined using spectrophotometric detection of a blue silico-molybdate complex, and converted to units of $\mathrm{mg} / \mathrm{m}^{3}$ assuming a molar mass of biogenic silica of $67.2 \mathrm{~g} / \mathrm{mol}$. The concentrations of lithogenic particles were estimated by measuring the concentration of particulate $\mathrm{Al}$ and assuming an $\mathrm{Al} / \mathrm{lithogenic}$ mass ratio of 0.0804 . Whereas $\mathrm{Al} /$ lithogenic mass ratios vary only slightly with particle source, by about $8 \%$ for upper and lower continental crust (Taylor and McLennan, 1995), dissolved Al is susceptible to scavenging, which could lead to overestimates of lithogenic material. However, overestimation of lithogenic particle concentration based on $\mathrm{Al}$ scavenging is mostly a concern for coastal samples Lam et al. (2015). Since we restrict our study to open-ocean stations, we estimate lithogenic mass based on the Al/lithogenic mass ratio. Total particulate $\mathrm{Al}$ (and $\mathrm{Ti}, \mathrm{Mn}$, and $\mathrm{Fe}$, all in units of $\mathrm{nM}$ ) were measured by complete digestion of the supor filters and polyester prefilters, followed by ICP-MS analysis.

Iron and manganese (oxyhydr)oxides were calculated by subtracting total particulate Mn and Fe from their respective lithogenic components. The lithogenic components were estimated using $\mathrm{Fe} / \mathrm{Ti}$ and $\mathrm{Mn} / \mathrm{Ti}$ mass ratios measured on aerosols collected along GA03 between Cape Verde and Mauritania $(\mathrm{Fe} / \mathrm{Ti}=8.7$ and $\mathrm{Mn} / \mathrm{Ti}=0.13$; Shelley et al. $(2015))$, and by multiplying these ratios by the concentration of $\mathrm{Ti}$ (assumed to be purely lithogenic) measured on oceanic particles. The difference between total particulate $\mathrm{Mn}$ and its lithogenic component was multiplied by the molar mass for birnessite $\left(\mathrm{MnO}_{2}=96.9 \mathrm{ng} / \mathrm{nmol}\right)$ to obtain the mass of $\mathrm{Mn}$ (oxyhydr)oxides per unit water volume. Likewise, the difference between total particulate Fe and its lithogenic component was multiplied by the molar mass for iron hydroxide $\left(\mathrm{Fe}(\mathrm{OH})_{3}=106.9 \mathrm{ng} / \mathrm{nmol}\right)$ to obtain the mass of Fe (oxyhydr)oxides per unit water volume. Hereafter, the Mn and Fe particulate concentrations obtained from these ratios are referred to as "Fe and Mn (oxyhydr)oxides".

The Th isotope data used in this study consist of measurements of ${ }^{228}$ Th (Charette et al., 2014), 
${ }^{230} \mathrm{Th}$ (Hayes et al., 2015b,a), and ${ }^{234} \mathrm{Th}($ Owens et al., 2015) in both the dissolved $(<1 \mu \mathrm{m})$ and total particulate phase $(>1 \mu \mathrm{m})$. We also use measurements of ${ }^{228}$ Ra activity (radioactive parent of ${ }^{228} \mathrm{Th} ;{ }^{228} \mathrm{Ra}$ data from Charette et al. (2015)) as well as estimates of ${ }^{234} \mathrm{U}$ (parent of ${ }^{230} \mathrm{Th}$ ) and ${ }^{238} \mathrm{U}$ (parent of ${ }^{234} \mathrm{Th}$ ) derived from salinity data and a fixed ${ }^{234} \mathrm{U} /{ }^{238} \mathrm{U}$ activity ratio for seawater. Details about the methods of sample collection and analysis and about the estimation of ${ }^{234,238} \mathrm{U}$ activities can be found in Lerner et al. (2017) and in references therein.

\subsection{Principal Component Analysis}

In this section, we explore whether the variability in the particulate phase data at our selected stations of GA03 can be summarized by only a few spatial patterns using principal component analysis (PCA). In broadest terms, PCA aims to find a few principal components (PCs), or linear combinations of the original variables, that explain a large proportion of the total variance in the dataset being considered (Rencher, 1998). This goal can be reached if the original variables are highly correlated, which is the case for our particle phase data (Fig. 2). Particularly, we find strong positive correlations between POC and PIC $(r=0.74)$, and between POC and bSi $(r=$ 0.70), which suggest that the variability in the particle composition data along GA03 could be approximated by a few PCs.

A PCA is conducted on the following particle phase data gathered at our selected stations: POC, PIC, bSi, lithogenic material, Mn (oxyhydr)oxides, and Fe (oxyhydr)oxides. Since the data occur at different geographic locations and depths, the PCs extracted from these data represent different spatial patterns along the section. PCs are extracted from both the covariance matrix and the correlation matrix of the data in order to document the effect of variable variance among different particulate phases (e.g., POC is typically present in seawater at much higher concentrations than Mn (oxyhydr)oxides). In both cases, the coefficients in a given PC are taken as measures of the importance of the different particulate phases for the corresponding pattern.

We find that the first two principal components explain $98 \%$ of the total variance in the particulate phase dataset if the PCs are extracted from the covariance matrix; if extracted from the correlation matrix, then the first two PCs explain over $69 \%$ of the total variance (Table 1). PC1, 
the first PC, is largely dominated by POC when the PCs are extracted from the covariance matrix; if extracted from the correlation matrix, the coefficients for POC, PIC, and bSi are all much closer in magnitude, though the coefficient for POC is still the largest (Fig. 3). Compared to PC1, PC2 represents a clear contrast between particles of different composition. PC2 extracted from both matrices is dominated by lithogenic material. If extracted from the correlation matrix, then $\mathrm{bSi}$, Mn, and Fe (oxyhydr)oxides have coefficients closer in magnitude to that for lithogenic particles.

Table 1: Percentages of total variance explained by principal components

\begin{tabular}{|c|c|c|c|c|c|c|}
\hline & PC1 & PC2 & PC3 & PC4 & PC5 & PC6 \\
\hline covariance & $57.3 \%$ & $41.2 \%$ & $1.2 \%$ & $0.3 \%$ & $0.0 \%$ & $0.0 \%$ \\
\hline correlation & $42.7 \%$ & $26.7 \%$ & $15.8 \%$ & $7.8 \%$ & $4.8 \%$ & $2.2 \%$ \\
\hline
\end{tabular}

Figure 4 shows the distribution along the GA03 section of the first two leading principal components. Interestingly, PC1 from both the covariance matrix and correlation matrix show systematic vertical variations at a given station, which likely reflects the effects of particle recycling along the water column. In addition, the values of PC1 at the four easternmost stations (GT11-24, GT1012, GT10-11, GT10-10) are in general noticeably different than those at the remaining stations. The salinity distribution along GA03 portrays pronounced upward bowing of isohalines near the crossover station GT11-24/GT10-12 (Jenkins et al., 2015), suggesting that these four stations are under the influence of the Mauritanian upwelling. In contrast to PC1, PC2 does not exhibit clear systematic variations with depth. On the other hand, both PC1 and PC2 tend to show a gradient between the four easternmost stations and the remaining stations along GA03.

In summary, the particle composition data collected along GA03 can be summarized by two principal components presenting systematic geographic and (or) vertical patterns along the section (Fig. 4). Although a precise interpretation of these patterns appears difficult, they seem to reflect the influences of particle recycling and of the Mauritanian upwelling or, more generally, of the proximity to the western African coast. 


\subsection{Estimates of Th Adsorption Rate Constant}

We estimate the vertical distribution of $k_{1}$ (below $\sim 100 \mathrm{~m}$ ) at each of the selected stations of GA03 by fitting a Th cycling model to radionuclide measurements (Fig. 1). The model as well as the inverse method used to fit the model to the data are briefly described here: details about the method can be found in Lerner et al. (2017). For convenience, subscripts $p$ and $d$ denote thorium activities in the particulate and dissolved phases, respectively.

We use a single-particle class model for thorium cycling that includes balance equations for ${ }^{228,230,234} \mathrm{Th}_{d}$ and bulk ${ }^{228,230,234} \mathrm{Th}_{p}$, i.e., ${ }^{228,230,234} \mathrm{Th}$ in both the small and large size particulate fractions. The thorium balance equations account for radioactive production, radioactive decay, Th adsorption onto particles, Th release from particles due to desorption and particle degradation, and particle sinking:

$$
\begin{aligned}
T\left(A_{d}\right) & =\lambda A_{\pi}+\left(k_{-1}+\beta_{-1}\right) A_{p}-\left(k_{1}+\lambda\right) A_{d} \\
T\left(A_{p}\right)+w \frac{\partial A_{p}}{\partial z} & =k_{1} A_{d}-\left(\beta_{-1}+k_{-1}+\lambda\right) A_{p} .
\end{aligned}
$$

Here, $A_{d}\left(A_{p}\right)$ represents the thorium isotope activity in the dissolved (particulate) phase (in units of $\left.\mathrm{dpm} \mathrm{m} \mathrm{m}^{-3}\right), A_{\pi}$ is the activity of the radioactive parent $\left(\mathrm{dpm} \mathrm{m}^{-3}\right), \lambda$ is the radioactive decay constant $\left(\mathrm{yr}^{-1}\right), k_{1}, k_{-1}$, and $\beta_{-1}$ are the apparent rate constants for Th adsorption, Th desorption, and particle degradation, respectively $\left(\mathrm{yr}^{-1}\right), w$ is the particle settling speed $\left(\mathrm{m} \mathrm{yr}^{-1}\right)$, and $z$ is depth (m). In accordance with previous models (e.g., Nozaki et al. (1981); Bacon and Anderson (1982)), we assume first-order kinetics for thorium adsorption, thorium desorption, and particle degradation. The lithogenic components of ${ }^{228,234} \mathrm{Th}$ are taken as negligible, while particulate ${ }^{230} \mathrm{Th}$ data are corrected for a contribution from a lithogenic source (for details, see Lerner et al. (2017)). Finally, the term $T(\cdot)$ in each equation represents the effects of unsteadiness, advection, and diffusion, i.e., 


$$
T\left(A_{d}\right) \equiv \frac{\partial A_{d}}{\partial t}+\boldsymbol{u} \cdot \nabla A_{d}-\nabla \cdot\left(\boldsymbol{k} \nabla A_{d}\right),
$$

where $t$ is time, $\mathbf{u}$ the vector velocity, and $\boldsymbol{k}$ a diffusion tensor. In this study, we assume $T(\cdot)=0$. Evidence for negligible effects of advection, diffusion, and, to some extent, unsteadiness at the stations analyzed here is provided in Lerner et al. (2017).

Equations (1a-1b) with $T(\cdot)=0$ are fit to the radiochemical data $\left({ }^{228,230,234} \mathrm{Th}_{d},{ }^{228,230,234} \mathrm{Th}_{p}\right.$, ${ }^{228} \mathrm{Ra}$, and ${ }^{234,238} \mathrm{U}$ ) below about $100 \mathrm{~m}$ at each selected station (see Table 1 of Lerner et al. (2017)) by adjusting the rate parameters $\left(k_{1}, k_{-1}, \beta_{-1}\right.$, and $\left.w\right)$ and the data themselves, given the uncertainties in the prior estimates of the rate parameters and in the data (more specifically, finite-difference analogs of equations (1a-b) with $T(\cdot)=0$ are fit to vertically interpolated data obtained from a minimum variance estimation procedure). The adjustments in the rate parameters and in the data can be different at different depths, such that a vertical profile of $k_{1}$, for example, is inferred at each station. Prior estimates of $k_{1}, k_{-1}, \beta_{-1}$ and $w$ are obtained from observational estimates of these parameters in distinct oceanic environments (see Table 2 of Lerner et al. (2017)). Note that, in contrast to Lerner et al. (2017), the present estimates of the rate parameters (e.g., $k_{1}$ ) are derived with no consideration of data of total particle concentration, calculated as the sum of the particle phase data (Lam et al., 2015), to ensure that the $k_{1}$ estimates are independent of these data. We show in Appendix A that both sets of $k_{1}$ estimates are very strongly correlated. The errors in the rate parameters and in the data derived by inversion are also estimated (Lerner et al., 2017).

The estimates of $k_{1}$ obtained by the inversion performed in this study are presented in Figure 5. It is seen that $k_{1}$ is generally larger in the upper $1000 \mathrm{~m}$ of the water column than below, and that $k_{1}$ values in the Mauritanian upwelling region (stations GT11-24, GT10-12, GT10-11, and GT10-10) exceed those to the west of this region. These vertical and lateral variations in $k_{1}$ are consistent with those found by Lerner et al. (2017) and generally exceed the errors in the $k_{1}$ estimates (not shown). 


\section{Results}

\subsection{Dependence of $\boldsymbol{k}_{1}$ on Particle Composition: Additive Model}

In this section, we use multiple linear regression to determine the dependence of $k_{1}$ upon particle composition. Before proceeding with the regression analysis, two questions regarding the particle composition data arise. A first question is whether to normalize the particle composition data to bulk particle concentration. Previous studies on the relationship between $K_{D}$ and particle composition have related $K_{D}$ to one particulate phase, or a linear combination of particulate phases, normalized to the total particle concentration (e.g., Chase et al. (2002); Li (2005); Hayes et al. (2015a)). Consideration of particle phase data normalized to total particle concentration $(P)$ appears to have been motivated by the presence of $P$ in the defining expression for $K_{D}$, i.e., $K_{D}=A_{p} /\left(A_{d} P\right)$. However, since our estimates of $k_{1}$ do not consider $P$ data (section 2.2), there is no clear reason to normalize the particle phases by bulk particle concentration in this study. Hence, we explore the dependence of $k_{1}$ on particle phase concentrations expressed in units of mass of particles of a certain type divided by water volume $\left(\mathrm{mg} \mathrm{m}^{-3}\right)$.

A second question is whether each particle phase should be treated as an individual regressor. As shown in Figure 2a, there is strong correlation among the biogenic phases. If strongly correlated variables are used as regressors in multiple regression, a situation called multicollinearity, then the individual estimates of the regression coefficients can be unstable (i.e., overly sensitive to the data values) and suffer from excessive variance (Rencher, 1998; Keith, 2014). Multicollinearity can thus lead to difficulties in the interpretation of regression coefficients. To reduce the influence of multicollinearity from the regression of $k_{1}$ against the particle phases, we lower the number of regressors to four. These include (i) the sum of the biogenic phases (POC+PIC+bSi, hereafter referred to as biogenic particles or "bio" for brevity), (ii) lithogenic material ("litho"), (iii) Mn (oxyhydr)oxides ("Mn"), and (iv) Fe (oxyhydr)oxides ("Fe"). As shown in Figure 2b, the correlation coefficients for this group of regressors do not exceed 0.5 . Therefore, we proceed with a model of $k_{1}$ as a linear 
combination biogenic particles, lithogenic material, and $\mathrm{Mn}$ and $\mathrm{Fe}$ (oxyhydr)oxides:

$$
k_{1}=a_{0}+a_{1}[b i o]+a_{2}[l i t h o]+a_{3}[M n]+a_{4}[F e]+\epsilon,
$$

where $a_{i}(i=0,1,2,3,4)$ are regression coefficients and $\epsilon$ is an error term representing the error in $k_{1}$ and the unmodeled variability. The regression model (3), referred to below as model I, posits that the effects of the particle phases on $k_{1}$ are additive. We regress $k_{1}$ against particle composition using ordinary least squares (OLS), which does not consider the error (co)variances for $k_{1}$ and the regressors ([bio], [litho], $[M n]$, and $[F e]$ ). In section 4.3, we document the effect of these errors on the regression.

The estimates of the regression coefficients $\left(a_{1}, a_{2}, a_{3}, a_{4}\right)$ and their standard errors are listed in Table 2 (first row; see also Table S1), and the best fit is shown in Figure 6a.

Table 2: Regression coefficients \pm 1 standard error $\left(\mathrm{yr}^{-1} \mathrm{~m}^{3} \mathrm{mg}^{-1}\right)$ for model I

\begin{tabular}{|l|c|c|c|c|}
\hline & bio & litho & Mn & Fe \\
\hline all stations $(\mathrm{n}=63)$ & $0.52 \pm 0.08(<0.01)^{a}$ & $0.05 \pm 0.10(0.65)$ & $-44.62 \pm 49.11(0.36)$ & $14.56 \pm 18.01(0.42)$ \\
\hline western stations $(\mathrm{n}=35)$ & $0.14 \pm 0.07(0.06)$ & $0.03 \pm 0.10(0.76)$ & $21.24 \pm 34.92(0.54)$ & $-1.24 \pm 11.82(0.92)$ \\
\hline eastern stations $(\mathrm{n}=28)$ & $0.58 \pm 0.15(<0.01)$ & $-0.31 \pm 0.29(0.29)$ & $-3.31 \pm 107.94(0.98)$ & $10.38 \pm 36.21(0.77)$ \\
\hline
\end{tabular}

a. Values in parentheses are $p$-values.

We find that the multiple correlation $R$ is 0.71 , with $p<0.01$, i.e., up to $0.71^{2}=50 \%$ of the variance in $k_{1}$ can be explained by particle composition $(n=63)$. Moreover, only the regression coefficients for biogenic particles is significant at the 0.05 level.

While a strong relationship between $k_{1}$ and particle composition is observed $(R=0.71$ with $p<0.01$, this relationship may not hold across all our selected stations. Stations in the Mauritanian upwelling region (GT11-24, GT10-12, GT10-11, and GT10-10) show large concentrations of lithogenic material, POC, and bSi compared to those at the other stations of GA03 (Lam et al., 2015). Our PCA of the particle data reveals a compositional contrast between stations west and east of GT11-24 (section 2.2). To test whether different regions sampled along GA03 are characterized by different relationships between $k_{1}$ and particle composition, we perform two multiple 
linear regressions: one for stations west of GT11-24 (Fig. 1), and another for stations east of, and including, station GT11-24. For simplicity, these two groups of stations are referred below to as "western" and "eastern" stations, respectively.

\subsubsection{Western and Eastern Stations}

For the western stations, the multiple correlation between $k_{1}$ and the particle phase data (Fig. 6b) amounts to $R=0.51$, with $p=0.05(n=35)$. The regression coefficient for the biogenic particles is the most significant among the different particulate phases, although none of the coefficients for this regression are significant at the 0.05 level (Table 2).

For the eastern stations, the multiple correlation between $k_{1}$ and particle phase data (Fig. 6c) reaches a value of $R=0.77$, with $p<0.01(n=28)$. Here, the regression coefficient for the biogenic phases is significant at the 0.05 level and the remaining regression coefficients are not significant at this level (Table 2). Overall, these results indicate that the strength of the correlation between the Th adsorption rate constant and particle composition varies along the GA03 section, i.e., the correlation is relatively weak for the western stations and stronger for the eastern stations.

\subsubsection{Critique of Model I}

Two issues emerge with the application of the additive model (model I) to describe the dependence of $k_{1}$ on particle composition at our selected stations of GA03. First, the presence of negative regression coefficients for some of the particle types (Table 2) is troubling: one would not expect the specific rate of adsorption of a metal onto particles to decrease with increasing particle concentration, regardless of particle phase. Indeed, adding particles of any type should increase the number of surface sites for thorium to attach to, and thus increase $k_{1}$. On the other hand, this reasoning does not consider the correlations between particle phases (Fig. 2b), i.e., a negative relationship between $k_{1}$ and a particle type (e.g., Mn (oxyhydr)oxides) may not be causal but rather reflect the simultaneous removal of another particle type (e.g., biogenic particles) characterized by a positive regression coefficient. Moreover, none of the negative regression coefficients differ 
significantly from $0 \mathrm{yr}^{-1} \mathrm{~m}^{3} \mathrm{mg}^{-1}$ (Table 2). Nevertheless, the inference of negative coefficients is intriguing, for it implies that $k_{1}$ can, at least in principle, be negative for some combinations of the particle phase concentrations.

Another issue with the application of the additive model is the appearance of variable variance (heteroscedasticity) in some of the plots of $k_{1}$ derived by inversion against $k_{1}$ derived by regression (Fig. 6a-c). Using a Breusch-Pagan test, we find evidence for significant heteroscedasticity for each group of stations ( $p<0.05 ;$ Madansky, 1988; p.81). When heteroscedasticity is present, the standard errors of the regression coefficients may be unreliable (Greene, 2012; p.299).

\subsection{Dependence of $k_{1}$ on Particle Composition: Multiplicative Model}

A possible remedy to the two foregoing issues is to assume the following relationship between $k_{1}$ and the particle phases:

$$
\ln \left(k_{1}\right)=b_{0}+b_{1} \ln [b i o]+b_{2} \ln [\operatorname{litho}]+b_{3} \ln [M n]+b_{4} \ln [F e]+\epsilon
$$

where $b_{i}(i=0,1,2,3,4)$ are another set of regression coefficients and $\epsilon$ accounts for the error in $\ln \left(k_{1}\right)$ and for unmodeled variability. Using logarithms for the regressand and the regressors both prevents the inference of negative regressand estimates and reduces variations in variance. Taking the exponential of each side of equation (4) yields

$$
k_{1} \propto[\text { bio }]^{b_{1}}[l i t h o]^{b_{2}}[M n]^{b_{3}}[F e]^{b_{4}} \epsilon .
$$

That is, the effects of the particle phases on $k_{1}$ are now considered as multiplicative with a multiplicative error. Hereafter, the regression model (4) is referred to as model II.

The estimates of the regression coefficients $\left(b_{1}, b_{2}, b_{3}, b_{4}\right)$ and their standard errors for all stations are listed in Table 3 (first row; see also Table S2), and the best fit is shown in Figure 6d.

We find that, for the multiplicative model, the multiple correlation for all stations is $R=0.71$, with $p<0.01$ ( $n=63)$. The regression coefficient for biogenic particles is significant at the 0.05 level, while the remaining regression coefficients are not significant at this level. These results are 
Table 3: Regression coefficients \pm 1 standard error for model II

\begin{tabular}{|l|c|c|c|c|}
\hline & bio & litho & Mn & Fe \\
\hline all stations $(\mathrm{n}=63)$ & $1.03 \pm 0.20(<0.01)^{a}$ & $0.35 \pm 0.20(0.08)$ & $0.13 \pm 0.31(0.68)$ & $0.01 \pm 0.03(0.61)$ \\
\hline western stations $(\mathrm{n}=35)$ & $0.32 \pm 0.27(0.22)$ & $-0.17 \pm 0.31(0.58)$ & $0.92 \pm 0.42(0.03)$ & $0.03 \pm 0.03(0.35)$ \\
\hline eastern stations $(\mathrm{n}=28)$ & $1.45 \pm 0.29(<0.01)$ & $-0.46 \pm 0.47(0.32)$ & $-0.20 \pm 0.41(0.62)$ & $-0.01 \pm 0.04(0.86)$ \\
\hline
\end{tabular}

$a$. Values in parentheses are $p$-values.

similar to those obtained from model I (section 3.1).

\subsubsection{Western and Eastern Stations}

For the western stations, the multiple correlation between $k_{1}$ and the particle phase data (Fig. 6e) amounts to $R=0.62$, with $p<0.01(n=35)$. Notably, only the regression coefficient for Mn (oxyhydr)oxides is significant at the 0.05 level.

For the eastern stations, the multiple correlation between $k_{1}$ and the particle phase data (Fig. 6f) reaches a value of $R=0.82$, with $p<0.01$ ( $n=28$ ). In contrast to the western stations, only the regression coefficient for biogenic particles is significant at the 0.05 level. Thus, as for model I, model II shows that the correlation between Th adsorption rate constant and particle composition is stronger for the eastern stations than for the western stations. On the other hand, in contrast to model I, model II shows that Mn (oxyhydr)oxides are the only significant regressor for the western stations, whereas in both models the biogenic particles are the only significant regressor for the eastern stations.

\subsubsection{Resolution of Model I Issues}

As for model I, some of the regression coefficients for model II are negative, although none of them are significantly so (Table 3). However, unlike for model I, negative regression coefficients for the multiplicative model do not imply that $k_{1}$ can be negative, since a regression based on logarithms ensures that regressand estimates remain positive definite for any combination of regressor values. Moreover, heteroscedasticity is less apparent (compare Figs. 6a-6c with Figs. 6d-6f) and not significant $(p>0.05)$ when the relationship between $k_{1}$ and the particle phases is described using a multiplicative model. Hence, the regression and correlation statistics seem more robust for model II than for model I. 


\section{Discussion}

Our results show that a multiplicative model appears to provide a better description than an additive model of the effects of particle phases on the apparent rate constant of Th adsorption onto particles along GA03. They also show that biogenic particles are a significant regressor in this model, except for the western stations where Mn-rich particles are the only significant regressor. In fact, the fits of the multiplicative model to the particle data are significantly different for both the eastern and western stations according to an F test ( $p=0.03$; Seber and Lee, 1992; p. 100).

\subsection{Relative Importance of Different Particulate Phases}

In this section, we attempt to elucidate the relative contribution of different particle phases to the variability in our $k_{1}$ estimates along GA03. The difficulty in this task lies in the remaining correlation between the particle types used as regressors (Fig. 2b), preventing a confident assignment of the phases that exert a dominant influence on $k_{1}$. To address this issue, we conduct a relative importance analysis, a technique which can provide estimates of the contribution of correlated regressors to the explained variance of a regressand.

In his review on techniques used to evaluate the relative importance of regressors, Grömping (2007, p. 140) noted that there is a "lack of an accepted mainstream methodology for the important task of relative importance investigations." Given an apparent lack of consensus, we apply two methods for evaluating the relative importance of the particle phases. One method, referred to as averaging over orderings (AOO) (Kruskal, 1987), averages partial correlation coefficients obtained from every possible ordering of the regressors. The other method, termed dominance analysis (DA) (Azen and Budescu, 2003), averages the contribution to the squared multiple correlation $R^{2}$ by a regressor over models encapsulating every possible subset of regressors. Both of these analyses are explained briefly in Appendix B.

Figure 7 shows values of relative importance $(R I)$ from both analyses for each particle phase and for each group of stations. Notably, the ranking of the particle phases is the same for the two methods. It is also the same for models I and II, with the exception that, at the western stations, Mn (oxyhydr)oxides have the highest $R I$ value for model II but the second highest value 
for model I. However, since model I appears questionable (section 3.2.2), we focus our discussion on the relative importance values for model II.

For all stations and stations in the Mauritanian upwelling region, biogenic particles are the most important regressor $(R I=0.41$ for $\mathrm{AOO}$ and $R I=0.36$ for DA). In contrast, for the western stations, the most important regressor is Mn (oxyhydr)oxides, with $R I=0.24$ for AOO and $R I=$ 0.22 for DA, i.e., about double the $R I$ value for biogenic particles according to both methods. Thus, the results from relative importance analysis suggest that the biogenic particles (POC, PIC, and bSi) dominate Th scavenging in the Mauritanian upwelling region, whereas Mn (oxyhydr)oxides dominate Th scavenging west of this region along GA03.

An interesting observation is that the groups of stations where biogenic particles dominate the explained variance in $k_{1}$ are also those displaying the largest $R^{2}$ values. Indeed, as shown in section 3 , the variance of $k_{1}$ explained by particle composition is higher for the eastern stations $\left(R^{2}=0.67\right)$ and for all selected stations $\left(R^{2}=0.51\right)$ than for the western stations $\left(R^{2}=0.39\right)$. Moreover, the concentrations of two of the three types of biogenic particles, POC and bSi, increase eastward in the upper $500 \mathrm{~m}$ towards the Mauritanian upwelling region (Lam et al., 2015). This finding suggests that the influence of the biogenic phases on the specific rate of Th adsorption onto particles is relatively large in waters where these types of particles are abundant.

To our knowledge, no previous studies exist on the effect of particle composition on the adsorption rate constant of Th onto marine particles $\left(k_{1}\right)$. In the absence of such studies, we compare our results to previous investigations on the distribution coefficient, $K_{D}$, derived for different particle phases, with the understanding that $k_{1}$ and $K_{D}$ are different concepts. Our results appear qualitatively consistent with the positive relationship between $K_{D}$ and $\% \mathrm{CaCO}_{3}$ found by Chase et al. (2002), though these authors also found that $K_{D}$ decreases with increasing \% opal. $\mathrm{Li}$ (2005), using the composition of bulk particles in sediment traps deployed in the Middle Atlantic Bight, the Southern Ocean, and the Equatorial Pacific, showed that $K_{D}$ was generally larger for organic carbon than for lithogenic material. The values of $K_{D}$ for each particle phase, however, varied across oceanic regions: $K_{D}$ was larger for lithogenic material than for organic matter in the South- 
ern Ocean and Equatorial Pacific, whereas the opposite result was observed in the Middle Atlantic Bight (Li, 2005). Quigley et al. (2002) found that partition coefficients for Th were larger for colloidal organic matter than for Mn and Fe (oxyhydr)oxides. They also found, from measurements of Th on colloids collected from the Gulf of Mexico and Galveston Bay, that the partition coefficient for colloids generally increases with the weight fraction of carbohydrate present in the colloidal fraction.

Using data from the GA03 section, Hayes et al. (2015a) estimated distribution coefficients for ${ }^{230} \mathrm{Th}$ and regressed these estimates against fractional contributions of particle composition (POC, bSi, lithogenic material, Fe, and Mn, all expressed in \% particulate mass fraction). They found that $K_{D}$ values for $\mathrm{Mn}$ and $\mathrm{Fe}$ (oxyhydr)oxides exceed those for the other particle types by one to two orders of magnitude. Among the remaining particle phases, they found that $K_{D}$ for $\mathrm{CaCO}_{3}$ was largest. Here, we find (for model II) that the biogenic phases (POC+PIC+bSi) are the most important regressors for $k_{1}$ at all stations and eastern stations, while Mn-rich particles are the most important at western stations (Fig. 7). We also find that the lithogenic material is not important compared to the biogenic phases (Fig. 7), whereas Hayes et al. (2015a) found lithogenic material to have $K_{D}$ values of a similar magnitude to $\mathrm{CaCO}_{3}$.

The comparison of our results with those of Hayes et al. (2015a) is difficult for several reasons, three of which are listed below. First, whereas $K_{D}$ values for Th are generally higher for (oxyhydr)oxides than for the biogenic phases present in oceanic waters (Anderson et al., 1992; Guo et al., 2002; Geibert and Usbeck, 2004; Lin et al., 2014; Hayes et al., 2015a), our analysis excludes marginal, near-bottom, and hydrothermal plume regions where Mn and Fe (oxyhydr)oxides significantly contribute to total particle concentration (Lam et al., 2015). For example, the largest $k_{1}$ estimate reported by Lerner et al. (2017) (see their Figure 12), near the TAG hydrothermal vent at station GT11-16 (excluded from this analysis), coincides with the largest concentrations of Fe (oxyhydr)oxides (Lam et al., 2015). Thus, it is likely that the relatively low importance of the (oxyhydr)oxide phases for Th scavenging, inferred here for all stations and the eastern stations, stems from the exclusion of samples presenting high concentrations of these phases. 
Second, if several assumptions are made in the Th isotope budget, including steady state, then the relationship between $k_{1}$ and $K_{D}$ involves the rate constants for Th desorption $\left(k_{-1}\right)$ and particle degradation $\left(\beta_{-1}\right)$, i.e., $K_{D}=k_{1} /\left(\left(k_{-1}+\beta_{-1}\right) P\right)$. Lerner et al. (2017) showed that, among the selected stations along GA03, $k_{-1}$ and $\beta_{-1}$ vary geographically, and generally increase with bulk particle concentration. Thus, even restricting the analyses of $k_{1}$ and $K_{D}$ values to the same set of stations would not necessarily lead to the same ordering of regression coefficients.

Finally, whereas Hayes et al. (2015a) derived $K_{D}$ values for each of the particle phases reported by Lam et al. (2015), we regressed $k_{1}$ against the sum of the biogenic phases, lithogenic material, and $\mathrm{Mn}$ and $\mathrm{Fe}$ (oxyhydr)oxides (model I), or we regressed $\ln \left(k_{1}\right)$ against the natural logarithms of these phases (model II). As a result the sensitivity of $k_{1}$ to the particle phases as estimated in this study cannot easily be compared to the variation of $K_{D}$ among the six particle phases (POC, PIC, bSi, lithogenic material, and Mn and Fe (oxyhydr)oxides) as reported by Hayes et al. (2015a).

\subsection{Kinetic Consistency of Additive and Multiplicative Models}

In this section, we discuss the ability of the additive and multiplicative models for $k_{1}$ to realistically describe the kinetics of Th sorption onto marine particles. Consider first model I, where the effects of different particle phases on $k_{1}$ are assumed to be additive. This model can be rationalized by considering a set of sorption reactions for Th onto different particle phases, each consisting of one elementary step:

$$
\begin{gathered}
S(1) X+T h \longrightarrow S(1) T h+X \\
\vdots \\
S(n) X+T h \longrightarrow S(n) T h+X
\end{gathered}
$$

Here, $S(1), \ldots, S(n)$ represent particle surfaces for $n$ different particle phases, and $X$ represents any chemical species that exchanges with thorium (e.g., $\mathrm{H}^{+}, \mathrm{Mg}^{2+}$, or $\mathrm{Na}^{+}$). For simplicity, we have ignored the electrical charges on thorium and $X$. The rate of disappearance of Th from 
solution in the $i$ th reaction of the set (6) is:

$$
\left(\frac{d[T h]}{d t}\right)_{i}=-k_{1, i}[S(i) X][T h]
$$

where $k_{1, i}$ is a second-order rate constant. Summing the rates of thorium disappearance from solution for all sorption reactions in (6) yields:

$$
\frac{d[T h]}{d t}=-\left(k_{1,1}[S(1) X]+\ldots+k_{1, n}[S(n) X]\right)[T h] .
$$

From this equation, a pseudo, first-order rate constant can be defined:

$$
k_{1}=k_{1,1}[S(1) X]+\ldots+k_{1, n}[S(n) X] \text {, }
$$

which is formally analogous to the additive regression model (equation (3)). Thus, the additive model for $k_{1}$ can be kinetically grounded by considering a set of simultaneous sorption reactions, with the important and obvious caveat that these reactions do not consider any potential interaction among the particle phases.

Consider now model II, where the effects of different particle phases on $k_{1}$ are assumed to be multiplicative. Here we envision a situation in which thorium and $n$ different particle phases are interacting simultaneously (Stumm and Morgan, 1996, p. 65):

$$
\begin{aligned}
& v_{1} \mathrm{~S}(1) \mathrm{X}+\ldots+v_{n} \mathrm{~S}(\mathrm{n}) \mathrm{X}+\mathrm{Th} \longrightarrow \\
& w_{1} \mathrm{~S}(1) \mathrm{Th}+\ldots+w_{n} \mathrm{~S}(\mathrm{n}) \mathrm{Th}+ \\
& w_{n+1}[\mathrm{~S}(1)+\mathrm{S}(2)] \mathrm{Th}+\ldots+w_{n+m}[\mathrm{~S}(1)+\mathrm{S}(2)+\ldots \mathrm{S}(\mathrm{n})] \mathrm{Th}+\left(v_{1}+\ldots v_{n}\right) \mathrm{X} .
\end{aligned}
$$

In this reaction, $\left(v_{1}, \ldots, v_{n}\right)$ and $\left(w_{1}, \ldots, w_{n+m}\right)$ are stoichiometric coefficients, and $m$ is the number of possible combinations of particle surfaces. Assuming for the moment that the chemical 
equation (10) is an elementary step, the rate of disappearance of thorium from solution is:

$$
\frac{d[T h]}{d t}=-\left\{k_{1, c}[S(1) X]^{v_{1}} \ldots[S(n) X]^{v_{n}}\right\}[T h]
$$

where $k_{1, c}$ is a high-order rate constant. The factor between curly brackets can be used to define another pseudo first-order rate constant $k_{1}$,

$$
k_{1}=k_{1, c}[S(1) X]^{v_{1}} \ldots[S(n) X]^{v_{n}} .
$$

This alternative expression of $k_{1}$ is formally analogous to the multiplicative model (equation $5)$.

Thus, like the additive model, the multiplicative model for $k_{1}$ could also be justified kinetically at first glance. However, the assumption that the chemical equation (10) is an elementary step may be severely questioned, as the probability of a simultaneous encounter of four different types of particles and a thorium cation is extremely low. For example, Stumm and Morgan (1996) noted that even an elementary reaction involving three species is infrequent in solution. Thus, although both the additive model and the multiplicative model could on first consideration be justified kinetically, each of these models is questionable - the first because it neglects interactions between different particulate phases and the second because it implies the simultaneous collision of large number of reactants in solution.

In summary, the additive and multiplicative models of Th adsorption onto particles seem to represent two limiting cases. Whereas model I neglects particle interactions, model II posits the simultaneous interaction of all particle phases with thorium in solution. A hybrid model that expresses $k_{1}$ as a sum of terms, with some of the terms proportional to a product of concentrations of different particle phases, might provide a more credible description of the kinetics of Th attachment to particles. However, identifying and testing the appropriateness of such a model is beyond the scope of this study. It should also be stressed that multiple phenomena could lead to formulations of models for $k_{1}$ that are fundamentally different than those considered here. Such 
phenomena include, for example, the coagulation of colloidal phases (Morel and Gschwend, 1987; Honeyman and Santschi, 1989), changes in the chemical composition of POM, and the coating of particles by organic material

\subsection{Reduced Models}

Although a multiplicative model can be challenged, it should be noted that equation (5) includes the possibility that several exponents vanish; should only one or two exponents be significantly different from zero, then model II would provide a more plausible description of Th sorption onto particles. Table 3 shows that, when considering results derived for all stations or the eastern stations, only the exponents for the biogenic phases are significantly different from zero. For both groups of stations, then, we may approximate equation (5) as:

$$
k_{1}=k_{1, c}[b i o]^{b_{1}} .
$$

For all stations and the eastern stations, we estimate that $b_{1} \geq 1$ (Table 3). Thus equation (13) is similar to the dependence of $k_{1}$ on bulk particle concentration $(P)$ found by Lerner et al. (2017), $k_{1} \propto P^{b}$ with $b \geq 1$. A nonlinear relationship between biogenic particle concentration and surface site concentration may explain an exponent $b_{1} \neq 1$. The chemical quality of particulate organic matter (POM) may also play a role. If labile POM is assumed to more efficiently adsorb thorium than semi-labile or refractory POM, then changes in POM lability with depth, as has been reported in multiple studies (Wakeham et al., 1997; Hedges et al., 2000; Lutz et al., 2002; Sheridan et al., 2002; Collins et al., 2015), could conceivably also result in a nonlinear relationship between $k_{1}$ and the concentration of biogenic particles. For example, organic molecules with carboxylic acid funtional groups, in particular acid polysaccharides, have a strong affinity for thorium (Quigley et al., 2001, 2002; Santschi et al., 2003; Quiroz et al., 2006; Santschi et al., 2006). Sheridan et al. (2002) reported that the weight fractions of amino acids and fatty acids, which can include carboxylic acid functional groups, in suspended particles decrease with depth along the mesopelagic zone ( 200-1000 m) in the Equatorial Pacific.

Although the nature of POC along GA03 has not been characterized, a change in the compo- 
sition of POC may also explain differences in the sensitivity of $k_{1}$ to the biogenic particles at the eastern vs. western stations (Table 3). POC at stations from the Mauritanian upwelling region may comprise a larger fraction of fresh and labile material with different surface functional groups than POC at the western stations. If POC at the western stations was characterized by fewer reactive functional groups than POC at the eastern stations, then the biogenic particle phases would become relatively less important for Th adsorption at the western stations.

At the western stations under model II, we find that the regression coefficient for Mn (oxyhydr)oxides is the only one that is significant at the 0.05 level (Table 3 ). Thus, for this group of stations, we may approximate equation (5) as:

$$
k_{1}=k_{1, c}[M n]^{b_{3}}
$$

For the western stations, we estimate that $b_{3}=0.92 \pm 0.42$, which is close to and not significantly different from 1 (Table 3 ). The shift in the dominant phase influencing $k_{1}$ from biogenic particles at the eastern stations to Mn (oxyhydr)oxides at the western stations coincides with an increase in the average contribution of $\mathrm{Mn}$ (oxyhydr)oxides to total particulate material from $=0.06 \pm 0.01 \%$ at the eastern stations to $=0.12 \pm 0.02 \%$ at the western stations, where averages and standard errors are calculated from the particle phase data used in this study (below 100 m; Lam et al. (2015)). Thus, $k_{1}$ appears more sensitive to Mn (oxyhydr)oxides when the fraction of this particle phase, relative to bulk particles, is increased. Below, we speculate on two potential reasons for the increased importance of Mn (oxyhydr)oxides at the western stations: the effect of surface area of the particles and the effect of surface charge of the particles.

Thorium may preferentially scavenge onto particles with a high surface area to mass ratio. Mn (oxyhydr)oxides have specific surface areas (SSAs) ranging from tens to hundreds $\mathrm{of}^{2} / \mathrm{g}$ (Toner et al., 2005), whereas the SSAs of biogenic particles appear to vary widely with particle type. Laboratory studies have shown that SSAs of biogenic carbonate particles are low, ranging between $1-10 \mathrm{~m}^{2} / \mathrm{g}\left(\right.$ Keir, 1990) while SSAs of biogenic silica vary between 10-250 $\mathrm{m}^{2} / \mathrm{g}$ (Dixit et al., 2001). It is unclear what the relevant range of SSAs for POC is in our study area. Thus particles with high 
Mn (oxyhydr)oxides and biogenic silica content would be expected to have more available surface area than particles with high carbonate content. Notice that, similarly to Mn (oxyhydr)oxides, Fe (oxyhydr)oxides can have SSAs up to hundreds of $\mathrm{m}^{2} / \mathrm{g}$ (Borggaard (1983); Hiemstra and Van Riemsdijk (2009)). Yet, this particle phase does not appear to significantly influence $k_{1}$ at the western or eastern stations (Table 3). One reason for the low influence of Fe (oxyhydr)oxides at both groups of stations may be this phase's lower contribution to total particle concentration at both the western $(0.07 \pm 0.00 \%)$ and eastern $(0.02 \pm 0.00 \%)$ stations (averages and standard errors calculated from data below $100 \mathrm{~m}$; Lam et al. (2015)). Speculatively, then, the increased importance of Mn (oxyhydr)oxides at the western stations might be due to a combination of its high specific surface area and its greater contribution to bulk particle concentrations, so that the encounter rate between Th-bearing molecules or ions in solution and Mn-rich particles site would be higher at these stations.

Mn (oxyhydr)oxides may also increase in importance at the western stations because of the electrical charge present at the surfaces of Mn-enriched particles. For example, while both Mn and Fe (oxyhydr)oxides have large SSAs, their surface charge at seawater $\mathrm{pH}$ differs. Potentiometric titrations performed at a variety of ionic strengths have shown that synthetic ferrihydrite (Fe oxydroxide) has near neutral surface charge whereas synthetic birnessite $\left(\mathrm{MnO}_{2}\right)$ is negatively charged (Peacock and Sherman, 2007; Moon and Peacock, 2013). Thorium, which exists in the +IV oxidation state in seawater (Choppin and Wong, 1998; Santschi et al., 2006), may have a stronger affinity towards negatively charged Mn (oxyhydr)oxides than neutrally charged Fe (oxyhydr)oxides.

Note that the increase in the fraction of Mn (oxyhydr)oxides from the eastern to western stations also coincides with a change in the composition of biogenic particles between these stations. The contribution of biogenic silica to bulk particle concentration amounts to $5.0 \pm 0.4 \%$ at the eastern stations and $2.5 \pm 0.3 \%$ at the western stations (averages and standard errors calculated from phase data below $100 \mathrm{~m}$; Lam et al. (2015)). In contrast, the contribution of carbonate to bulk particle concentration does not change significantly from the eastern stations $(3.3 \pm 0.4 \%)$ to the western stations $(3.9 \pm 0.9 \%)$. In addition to the larger SSAs of biogenic silica compared to those 
of biogenic carbonate particles, laboratory studies have shown that, at seawater $\mathrm{pH}$, carbonate particles are positively charged (Morse, 1986), but biogenic silica and organic matter are negatively charged (Niehof and Loeb, 1972; Hunter and Liss, 1979; Davis, 1982; Dixit et al., 2001). Assuming $k_{1}$ increases with either SSA or negative charge of particles, the effect on $k_{1}$ of non-biogenic particles relative to that of biogenic particles would thus be stronger at the western vs. the eastern stations, consistent with our results (Table 3). Thus, our study suggests the hypothesis that $k_{1}$ in the North Atlantic is at least partly controlled by particle phases with negatively charged surfaces: biogenic particles at the eastern stations and Mn (oxyhydr)oxides at the western stations.

\subsection{Paleoceanographic Implications}

In this section, the potential implications of our results for the interpretation of ${ }^{230} \mathrm{Th}$ measurements on bulk sediment samples are briefly discussed. Such measurements have found different applications in paleoceanography. For example, they are used to correct accumulation rates of constituents for the effects of sediment redistribution on the seafloor by bottom currents (for a review see, e.g., François et al. (2004)). In this approach, the accumulation rates are normalized to the flux of ${ }^{230} \mathrm{Th}$ scavenged from seawater, $F$, which is assumed to be equal to the rate of ${ }^{230} \mathrm{Th}$ radioactive production in the overlying water column,

$$
F=\lambda A_{\pi} Z
$$

Here, $\lambda$ is the ${ }^{230} \mathrm{Th}$ radioactive decay constant, $A_{\pi}$ is the ${ }^{234} \mathrm{U}$ activity, and $\mathrm{Z}$ is the local water depth. Expression (15) can be derived by summing equations (1-2) with $\mathrm{T}(\cdot)=0$, which yields an equation for total ${ }^{230} \mathrm{Th}$ activity,

$$
w \frac{d A_{p}}{d z}=\lambda A_{\pi}
$$

Integration of equation (16) from the surface $(z=0)$ to the bottom $(z=Z)$ and with the boundary condition $A_{p}=0 \mathrm{dpm} \mathrm{m}^{-3}$ at $z=0$ leads to (15), since $F=w A_{p}(Z)$. Naturally, the reversible exchange terms in (1a) and (1b) cancel out in the derivation of the equation for 
total ${ }^{230} \mathrm{Th}(16)$. As a result, at least under the assumptions under which (15) holds, the ${ }^{230} \mathrm{Th}$ normalization approach appears to be immune to variations in $k_{1}$ such as caused by variations in particle concentration and particle composition.

Such a conclusion, however, would not hold if any of the assumptions used to derived (15) are violated. For example, if the residence time of thorium with respect to scavenging (average residence time $\sim 20$ yrs, Henderson and Anderson (2003)) is close to or greater than the time scale for Th advection, then the assumption that $T(\cdot)=0$ would not hold, and the vertical flux of ${ }^{230} \mathrm{Th}_{p}$ may be sensitive to variations in $k_{1}$. This can be seen by including horizontal advection in equations (1a) and (1b), and by assuming the other terms in $T\left(A_{d}\right)$ and $T\left(A_{p}\right)$ are negligible:

$$
\begin{aligned}
u \frac{\partial A_{d}}{\partial x} & =\lambda A_{\pi}+k_{-1}^{*} A_{p}-k_{1} A_{d}, \\
u \frac{\partial A_{p}}{\partial x}+w \frac{\partial A_{p}}{\partial z} & =k_{1} A_{d}-k_{-1}^{*} A_{p},
\end{aligned}
$$

where $u$ is the velocity component along the horizontal coordinate $x$, and $k_{-1}^{*}=k_{-1}+\beta_{1}$. Note that radioactive decay rates have been omitted in (17a-17b), since they are very small compared to adsorption and desorption rates for the long-lived ${ }^{230} \mathrm{Th}$. Multiplying (17a) by $k_{1}$, applying the operator $u \frac{\partial}{\partial x}+k_{1}$ to $(17 \mathrm{~b})$, and summing the two resulting equations, yields the following equation for $A_{p}$ :

$$
u^{2} \frac{\partial^{2} A_{p}}{\partial x^{2}}+u w \frac{\partial^{2} A_{p}}{\partial x \partial z}+u\left(k_{1}+k_{-1}^{*}\right) \frac{\partial A_{p}}{\partial x}+w k_{1} \frac{\partial A_{p}}{\partial z}=k_{1} \lambda A_{\pi}
$$

Equation (18) is a second order linear partial differential equation with three terms that depend on the horizontal velocity $u$. If these terms are ignored, we recover equation (16), which does not include $k_{1}$. However, if these terms are retained, then $k_{1}$ would not cancel out from (18), i.e., adsorption onto particles would influence the distribution of ${ }^{230} \mathrm{Th}_{p}$ and hence the vertical settling flux of particulate ${ }^{230} \mathrm{Th}$ reaching the sediment.

Paired measurements of ${ }^{230} \mathrm{Th}$ and ${ }^{231} \mathrm{~Pa}$ on bulk sediment samples have been used to draw 
inferences about past changes in biological productivity (Kumar et al., 1993) and ocean circulation (Yu et al., 1996). The interpretation of sediment ${ }^{231} \mathrm{~Pa} /{ }^{230} \mathrm{Th}$ data in terms of ocean circulation is complicated by the uncertainties in the analysis of these data (Burke et al., 2011) and by the spatial variability in scavenging intensity (Hayes et al., 2015b). Since the present paper addresses the effects of particle composition on Th scavenging only, it appears inappropriate to comment on implications for the interpretation of sediment ${ }^{231} \mathrm{~Pa} /{ }^{230} \mathrm{Th}$ records. Nevertheless, by providing evidence that the specific rate at which Th attaches to particles varies along GA03, apparently in relation to particle concentration and particle composition, our study suggests that such variations may play a role in the distribution of sedimentary indicators based on ${ }^{230} \mathrm{Th}$.

\subsection{Importance of Errors}

Our previous results are based on a regression technique (OLS) that does not consider the error (co)variances in the particle data and $k_{1}$ estimates. However, these errors may significantly influence estimates of the regression coefficients. To document this influence, we use the Algorithm of Total Inversion (ATI). Whereas OLS is a standard procedure, the ATI is less commonly used and is described in detail in Appendix B. The regression coefficients estimated by ATI are reported in Tables 4 and 5, and the best fits are shown in Figure 8.

Table 4: Regression coefficients \pm 1 standard deviation $\left(\mathrm{yr}^{-1} \mathrm{~m}^{3} \mathrm{mg}^{-1}\right)$ for model I (ATI)

\begin{tabular}{|l|c|c|c|c|}
\hline & bio & litho & Mn & Fe \\
\hline all stations $(\mathrm{n}=63)$ & $0.35 \pm 0.07$ & $0.25 \pm 0.11$ & $-38.5 \pm 20.8$ & $103.5 \pm 14.4$ \\
\hline western stations $(\mathrm{n}=35)$ & $0.19 \pm 0.07$ & $0.17 \pm 0.16$ & $-27.4 \pm 20.1$ & $73.64 \pm 14.67$ \\
\hline eastern stations $(\mathrm{n}=28)$ & $0.58 \pm 0.24$ & $0.30 \pm 0.58$ & $-182.4 \pm 144.2$ & $176.5 \pm 62.7$ \\
\hline
\end{tabular}

Table 5: Regression coefficients \pm 1 standard deviation for model II (ATI)

\begin{tabular}{|l|c|c|c|c|}
\hline & bio & litho & Mn & Fe \\
\hline all stations $(\mathrm{n}=63)$ & $1.81 \pm 0.18$ & $0.16 \pm 0.20$ & $-2.03 \pm 0.53$ & $0.46 \pm 0.09$ \\
\hline western stations $(\mathrm{n}=35)$ & $1.27 \pm 0.20$ & $-0.37 \pm 0.20$ & $-0.40 \pm 0.38$ & $0.26 \pm 0.06$ \\
\hline eastern station $(\mathrm{n}=28)$ & $1.69 \pm 0.34$ & $-1.09 \pm 0.46$ & $1.03 \pm 0.54$ & $-0.22 \pm 0.06$ \\
\hline
\end{tabular}

For the biogenic phases, the coefficients obtained by the ATI differ from 0 by more than 2 standard deviations in all cases. This result is consistent with the finding from OLS that across all regression models (I and II ) and groups of stations (all stations, western stations, and eastern stations), $k_{1}$ has a positive relationship with biogenic particles which is generally significant at the 0.05 level. The sole exception to this result arises when OLS is used to fit model II at the western 
stations, for which the biogenic phase regression coefficient is not significant $(p=0.32)$. For the other particle types, the choice of regression technique significantly changes the estimated regression coefficients (compare Tables 2-3 with Tables 4-5). The coefficient for Fe (oxyhydr)oxides at all stations provides an extreme example, amounting to $14.56 \pm 18.01 \mathrm{yr}^{-1} \mathrm{~m}^{3} \mathrm{mg}^{-1}$ for OLS and to $103.5 \pm 14.4 \mathrm{yr}^{-1} \mathrm{~m}^{3} \mathrm{mg}^{-1}$ for the ATI (all stations, model I).

Notice that there is no a priori reason to prefer one regression method over another, since each has advantages and disadvantages. Ordinary least squares, while not considering the error (co)variances of the data and $k_{1}$ estimates, finds the best, unbiased linear fit to the data. In contrast to OLS, the ATI accounts for estimated errors in $k_{1}$ and the particle data. However, it can produce solutions which are (i) questionable if the regression problem is strongly nonlinear (i.e., if the errors in the regressors are substantial), (ii) biased, and (iii) very sensitive to prior statistics assumed for the regression coefficients (Appendix C).

\subsection{Particle Concentration vs. Particle Composition}

In this section, we test whether particle concentration and particle composition explain significantly different fractions of the variance in our $k_{1}$ estimates at the selected GA03 stations. We first perform this analysis for model II. Figure 9 shows the $k_{1}$ estimates derived in this paper vs. bulk particle concentration. A log-log scale is used to be consistent with model II. The Pearson correlation coefficient between $\ln \left(k_{1}\right)$ and $\ln (P)$ amounts to $r=0.71$ for all stations, 0.54 for stations west of GT11-24, and 0.77 for stations east of and including GT11-24. In comparison, the multiple correlation between $\ln \left(k_{1}\right)$ and a linear combination of the logarithms of particle phases for these groups of stations amounts to $R=0.71,0.62$, and 0.82 , respectively (section 3.1 ). To compare both sets of correlations, we conduct an $F$ test for the equality of the variance in $\ln \left(k_{1}\right)$ explained by $\ln (P)$ and by a linear combination of the logarithms of particle phases. The $p$ values are 0.95 for all selected stations, 0.23 for stations west of GT11-24, and 0.82 for stations east of and including GT11-24. A similar analysis for model I yields $p$ values of 0.09 for all selected stations, 0.63 for stations west of GT11-24, and 0.15 for stations east of and including GT11-24. Thus, for each group of stations and for each model, particle composition explains a proportion of 
variance in $k_{1}$ or $\ln k_{1}$ that is statistically indistinguishable at the 0.05 level from that explained by particle concentration.

However, the particle composition analysis brings additional insight into the mechanisms by which thorium adsorbs onto particles. For example, the better performance of the multiplicative compared to the additive model highlights the importance of interactions between particle phases. Moreover, the regression against particle composition illustrates the regional variability in the effectiveness of different particle phases at adsorbing thorium. For example, the importance of Mn (oxyhydr)oxides at the oligotrophic western stations, but not in the more productive, Mauritanian upwelling regions, suggests a difference in the interactions and/or chemical quality of particles between these two regions.

\section{Conclusion}

In this paper, we document the influence of particle composition on estimates of the rate constant of thorium adsorption onto particles $\left(k_{1}\right)$ at selected stations of the U.S. GEOTRACES North Atlantic section. Multiple linear regression analysis is applied to determine the sensitivity of $k_{1}$ to various particle phases (biogenic particles, lithogenic particles, Mn and Fe (oxyhydr)oxides). Two models for the dependence of $k_{1}$ on particle composition are considered: model I assumes that the effects of the different particle phases on $k_{1}$ are additive, whereas model II assumes that these effects are multiplicative. We apply these regression models to three groups of stations: (i) all selected stations, (ii) stations west of the Mauritanian upwelling, and (iii) stations within the Mauritanian upwelling.

We find that the variations in $k_{1}$ explained by the particle phase data depends on the group of stations considered and the model applied: $R^{2}=0.60(0.67)$ for model I (II) applied to the eastern stations, and $R^{2}=0.26(0.39)$ for model I (II) applied to the western stations. The estimates of the regression coefficients and their standard errors are sensitive to the consideration of errors in the particle data and $k_{1}$ estimates. Nonetheless, the regression coefficient estimate for biogenic particles is generally significant at the 0.05 level for both models I and II. A relative importance analysis reveals that the biogenic particles dominate the variability in $k_{1}$ explained by particle 
composition in the Mauritanian upwelling region, but that Mn (oxyhydr)oxides account for most of the explained variability in $k_{1}$ west of this region. We also find that the correlation between $k_{1}$ and particle composition is not significantly different from that between $k_{1}$ and particle concentration at the 0.05 level.

Our results thus suggest that the apparent rate constant $k_{1}$ may largely be driven by one particle type: biogenic phases for the stations in the Mauritanian upwelling region and $\mathrm{Mn}$ (oxyhydr)oxides for the stations east of this region. While this finding may appear to be at variance with Hayes et al. (2015a) and earlier studies on the relationship between $K_{D}$ and particle composition, it is important to emphasize that $K_{D}$ and $k_{1}$ are different concepts. On the one hand, $K_{D}$ is an empirical measure of the proportion of the metal bound to particles, given the concentrations of the metal in solution and the concentration of particles. On the other hand, $k_{1}$ represents an apparent first order rate constant for the adsorption of the metal onto particles. The expression $K_{D}=k_{1} /\left(\left(k_{-1}+\beta_{-1}\right) P\right)$, valid only under a set of assumptions (Honeyman et al., 1988; Lerner et al., 2017), shows that $K_{D}$ would carry information about the relative intensity of metal attachment to, and detachment from, particles, whereas $k_{1}$ would carry information about the rate of only one of these processes. In this perspective, $K_{D}$ and $k_{1}$ would play the same role as equilibrium and rate constants in the study of chemical reactions and provide complementary information about the scavenging of particlereactive metals in oceanic waters.

Finally the analysis presented here may grant us some insight into the nature of thorium adsorption onto particles in the North Atlantic. The importance of biogenic particles at the eastern stations may stem from the preferential adsorption of Th onto particulate matter with large amounts of carboxyl functional groups, while the importance of Mn (oxyhydr)oxides at the western stations may reflect preferential adsorption on Mn-rich particles with high specific surface area and/or negative surface charges. Whether similar results hold for other metals in the ocean, and their implications for the interpretation of thorium isotope measurements in the seawater and the sediments, remain to be investigated. 


\section{Acknowledgement}

We acknowledge the U.S. National Science Foundation for supporting this study (grant OCE1232578) and the U.S. GEOTRACES North Atlantic section ship time, sampling, and data analysis. The U.S. NSF also supported the generation of ${ }^{230}$ Th data (OCE-0927064 to LDEO, OCEO092860 to WHOI, and OCE-0927754 to UMN) and ${ }^{228,234}$ Th data (OCE-0925158 to WHOI). We thank the chief scientists of the GA03 section (Ed Boyle, Bill Jenkins, and Greg Cutter) as well as the captain, the crew, and the scientific party on the R/V Knorr, which completed this section. We are also grateful to the scientists and staff involved in the analysis of the thorium isotope and particle data. We also benefited from very useful discussions with Carl Lamborg (UCSC) and Philip M. Gschwend (MIT) on the kinetics of sorption reactions in aqueous media. 


\section{Appendix A}

In this study, we derive estimates of $k_{1}$ from the fit of a thorium cycling model (eqs. 1a-1b) to radionuclide data. The fit is achieved using a nonlinear programming technique using parameter values reported in Table A.1 of Lerner et al. (2017). We refer the reader to this previous work for details. In contrast to the present study, Lerner et al. (2017) obtained estimates of $k_{1}$ by fitting a model considering both thorium and particle dynamics to radionuclide and particle concentration data. In order to check for consistency between the two sets of estimates of $k_{1}$, we regress $k_{1}$ values obtained in this study against those obtained in Lerner et al. (2017) (Figure A1). We find that the slope of the OLS fit amounts to $1.25 \pm 0.09$. Thus, the $k_{1}$ estimates derived in this paper are in general slightly larger than those derived by Lerner et al. (2017), but the two sets of estimates are highly correlated $\left(R^{2}=0.99\right)$.

\section{Appendix B}

In this section, we briefly review the relative importance techniques of Kruskal (1987) and Azen and Budescu (2003); further details on these techniques can be found in these two papers.

\subsection{Averaging Over Orderings (AOO)}

To evaluate the importance of different regressors, Kruskal (1987) addressed the scenario in which there is no "natural ordering" of importance of the regressors. In this case, he suggested to take an average over all orderings. Using partial correlation coefficients as measures of importance, the method of AOO averages these coefficients obtained from every possible permutation of the regressors. When calculating the partial correlation between a regressor and regressand, the order of regressors determines whether the correlation takes into account the variance in the regressand explained by the other regressors. As an example, consider a case with only two particulate phases, $P_{1}$ and $P_{2}$. In that case, $\ln k_{1}$ is modeled as a linear combination of these two regressors:

$$
\ln \left(k_{1}\right)=a_{0}+a_{1} \ln \left(P_{1}\right)+a_{2} \ln \left(P_{2}\right)+\epsilon .
$$

To estimate the relative importance of $\ln P_{1}$, one averages the partial correlation coefficients 
between $\ln P_{1}$ and $\ln k_{1}$ over every possible order of $P_{1}$ and $P_{2}$. In this case, the regressors have only two possible orders: $P_{1}, P_{2}$ and $P_{2}, P_{1}$. For the first ordering, $P_{1}, P_{2}$, the partial correlation coefficient between $\ln k_{1}$ and $\ln P_{1}$ is simply the Pearson correlation coefficient between $\ln k_{1}$ and $\ln P_{1}, R_{k_{1}, P_{1}}$. For the second ordering, $P_{2}, P_{1}$, the partial correlation coefficient must take the variance in $\ln k_{1}$ explained by $\ln P_{2}$ into account:

$$
R_{k_{1}, P_{1} \cdot P_{2}}=\left(R_{k_{1}, P_{1}}-R_{k_{1}, P_{2}} R_{P_{1}, P_{2}}\right) / \sqrt{\left(1-R_{k_{1}, P_{2}}^{2}\right)\left(1-R_{P_{1}, P_{2}}^{2}\right)} .
$$

Here, $R_{k_{1}, P_{2}}$ is the Pearson correlation coefficient between $\ln k_{1}$ and $\ln P_{2}$, and $R_{k_{1}, P_{2}}$ is the Pearson correlation coefficient between $\ln P_{1}$ and $\ln P_{2}$. The relative importance of $P_{1}$ is then taken as the average of the two squared partial correlation coefficients,

$$
R I=0.5\left(R_{k_{1}, P_{1}}^{2}+R_{k_{1}, P_{1} \cdot P_{2}}^{2}\right)
$$

\subsection{Dominance Analysis}

Dominance analysis accounts for the correlation between regressors by averaging the contribution to $R^{2}$ by a regressor over models encapsulating every possible subset of regressors (Azen and Budescu, 2003). As an example, consider again the case with only two particulate phases:

$$
\ln \left(k_{1}\right)=a_{0}+a_{1} \ln \left(P_{1}\right)+a_{2} \ln \left(P_{2}\right)+\epsilon
$$

To estimate the relative importance of $\ln P_{1}$, take the average additional contribution of $\ln P_{1}$ to the explained variance over two models: (1) a null model with no contributions from $\ln P_{1}$ and $\ln P_{2}$, and (2) a model considering $\ln k_{1}$ as a linear function of $\ln P_{2}$. Respectively:

$$
\begin{array}{r}
\ln \left(k_{1}\right)=a_{0}+\epsilon, \\
\ln \left(k_{1}\right)=a_{0}+a_{2} \ln \left(P_{2}\right)+\epsilon .
\end{array}
$$


Denote $R_{n u l l}^{2}$ and $R_{P 2}^{2}$ as the squared correlation coefficients for models (23a) and (23b), respectively. Adding $\ln P_{1}$ to each model results in the following extended models,

$$
\begin{array}{r}
\ln \left(k_{1}\right)=a_{0}+a_{1} \ln \left(P_{1}\right)+\epsilon, \\
\ln \left(k_{1}\right)=a_{0}+a_{1} \ln \left(P_{1}\right)+a_{2} \ln \left(P_{2}\right)+\epsilon .
\end{array}
$$

Denote $R_{P 1}^{2}$ and $R_{\text {full }}^{2}$ as the squared correlation coefficients for models (24a) and (24b), respectively. The relative importance is then defined as the average contribution of $P_{1}$ to the explained variance, i.e.,

$$
R I_{P 1}=0.5\left(\left(R_{\text {full }}^{2}-R_{P 2}^{2}\right)+\left(R_{P 1}^{2}-R_{\text {null }}^{2}\right)\right)
$$

A similar expression is used for $R I_{P 2}$. Thus, dominance analysis breaks down the squared correlation of a multiple linear regression into contributions from the different regressors.

\section{Appendix C}

We account for the error (co)variances of the particle composition data and $k_{1}$ estimates using the Algorithm of Total Inversion (ATI; Tarantola and Valette, 1982). The ATI proceeds as follows. In equations (3) and (4) (section 3.2), the regression coefficients as well as the particle phase data are treated as unknowns. We construct a prior estimate of a vector $\boldsymbol{x}$ of unknowns, which is $\boldsymbol{x}_{0}$. The elements of $\boldsymbol{x}_{0}$ contain (i) prior estimates of the regression coefficients, and (ii) the particle measurements (bio, litho, $M n, F e$ ). We also construct a vector equation $\boldsymbol{f}(\boldsymbol{x})=\mathbf{0}$ which contains the regression equations (3) or (4). We then minimize the objective function

$$
J(\boldsymbol{x})=\left(\boldsymbol{x}-\boldsymbol{x}_{0}\right)^{\prime} \boldsymbol{C}_{0}^{-1}\left(\boldsymbol{x}-\boldsymbol{x}_{0}\right)+\boldsymbol{f}(\boldsymbol{x})^{\prime} \boldsymbol{C}_{f}^{-1} \boldsymbol{f}(\boldsymbol{x}) .
$$

Here $\boldsymbol{C}_{\mathbf{0}}$ and $\boldsymbol{C}_{f}$ are covariance matrices for the errors in $\boldsymbol{x}_{0}$ and in the model equations (eq. 3 or 4), respectively, and the primes are vector transposes. The error covariance matrix $\boldsymbol{C}_{0}$ is taken as 
diagonal. Its diagonal elements are the squared errors in the particle measurements (or the squared errors of the natural logarithm of these elements) and in the prior estimates of the regression coefficients. The matrix $C_{f}$ is based on the error (co)variances of $k_{1}$ derived by inversion (section 2.3). Thus we seek an estimate of $\boldsymbol{x}$ that is consistent with (i) its prior estimates, $\boldsymbol{x}_{0}$, given the error variances in $\boldsymbol{C}_{0}$, and (ii) the regression model (eq. 3 or 4), given the error covariances in $\boldsymbol{C}_{f}$.

The prior estimates of the regression coefficients in equation (3) or (4) are taken from Honeyman et al. (1988). These authors fit a power law, $k_{1}=k_{1, c} P^{b}$, to field data spanning a wide range of particle concentrations from $O\left(10 \mathrm{mg} \mathrm{m}^{-3}\right)$ to $O\left(10^{9} \mathrm{mg} \mathrm{m}^{-3}\right)$. The prior estimates for the regression coefficients $\left(a_{1}, \ldots, a_{4}\right)$ for model I are set to the value of $k_{1, c}=0.024 \mathrm{yr}^{-1} \mathrm{~m}^{3}$ $\mathrm{mg}^{-1}$ found by Honeyman et al. (1988), and the prior estimate for $a_{0}$ under model I is set to $0 \mathrm{yr}^{-1}$. For model II, the prior estimates of the regression coefficients $\left(b_{1}, \ldots, b_{4}\right)$ are set to the value of $b=0.58$ found by Honeyman et al. (1988), and the prior estimate for $b_{0}$ under model II is set to $\ln \left(k_{1, c}\right)=\ln \left(0.024 \mathrm{yr}^{-1}\left(\mathrm{~m}^{3} \mathrm{mg}^{-1}\right)^{0.58}\right)$. Since these prior estimates are poorly constrained, being based on a single study that considers the effect of particle concentration (not composition) on $k_{1}$, we set the prior estimates of their errors to be large, i.e., the prior estimates of the errors in the regression coefficients are three orders of magnitude greater than their absolute value (for $a_{0}$ under model $\mathrm{I}$, the error is set to $1000 \mathrm{yr}^{-1}$ ). With this choice, we find that the regression coefficient estimates are very poorly sensitive to the prior values, a desirable result.

The ATI solution at iteration $k_{i+1}$ is:

$$
\hat{\boldsymbol{x}}_{k+1}=\boldsymbol{x}_{0}+\boldsymbol{C}_{\mathbf{0}} \boldsymbol{F}_{k}^{\prime}\left(\boldsymbol{F}_{k} \boldsymbol{C}_{0} \boldsymbol{F}_{k}^{\prime}\right)^{-1}\left(\boldsymbol{F}_{k}\left(\hat{\boldsymbol{x}}_{k}-\boldsymbol{x}_{\mathbf{0}}\right)-\boldsymbol{f}\left(\hat{\boldsymbol{x}}_{\mathrm{k}}\right)\right),
$$

where $\boldsymbol{F}$ is a matrix whose elements are the partial derivatives of equations (3) or (4) with respect to the elements of $\boldsymbol{x}$, i.e., the element in the $i$ th row and $j$ th column of $\boldsymbol{F}_{k}$ is $\partial f_{i} / \partial x_{j}$. The solution error covariance matrix is estimated from

$$
\boldsymbol{C}_{k+1}=\boldsymbol{C}_{0}-\boldsymbol{C}_{0} \boldsymbol{F}_{k}^{\prime}\left(\boldsymbol{F}_{k} \boldsymbol{C}_{0} \boldsymbol{F}_{k}^{\prime}\right)^{-1} \boldsymbol{F}_{k} \boldsymbol{C}_{0}
$$


The matrix inversions in (A.2-A.3) are performed using LU decomposition.

We use two measures of goodness of fit. One is the fraction of the regression equations in $\boldsymbol{f}(\boldsymbol{x})=\mathbf{0}$ that are satisfied to within $\pm 2 \sigma_{k_{1}}$, where $\sigma_{k_{1}}$ is the estimated error in $k_{1}$ obtained by inversion. The other is the number of particle phase measurements that are fit to within 2 standard deviations by the model. We count a particle phase measurement as fit by the model I or II if the corresponding normalized residual is less than 2 in absolute magnitude. A normalized residual is defined as $\left(\hat{x}_{i}-x_{0, i}\right) / \sigma_{0, i}$, where index $i$ refers to a particular sample and $\sigma_{0, i}$ is the corresponding error (Lam et al., 2015). We find that, when the error (co)variance in the particle data and $k_{1}$ estimates are considered, between 96 and 100\% of the particle phase data are fit to within two standard deviations in the data, and that between 97 and $100 \%$ of the regression equations are satisfied to within two standard deviations in the $k_{1}$ or $\ln \left(k_{1}\right)$ estimates, where the ranges reflect the different models and different groups of stations. Thus, the regression coefficients obtained from ATI appear generally consistent with both the particle data and the $k_{1}$ or $\ln \left(k_{1}\right)$ estimates given their respective error estimates. 


\section{References}

Anderson, H. L., R. François, and S. B. Moran (1992), Experimental evidence for differential adsorption of Th and Pa on different solid phases in seawater, EOS, 73, 270.

Anderson, R. F., M. P. Bacon, and P. G. Brewer (1983), Removal of ${ }^{230}$ Th and ${ }^{231} \mathrm{~Pa}$ from the open ocean, Earth Planet. Sci. Lett., 62, 7-23.

Azen, R., and D. V. Budescu (2003), The dominance analysis approach for comparing predictors in multiple regression, Psychol. methods, 8(2), 129-148.

Bacon, M. P., and R. F. Anderson (1982), Distribution of thorium isotopes between dissolved and particulate forms in the deep sea, J. Geophys. Res. Oceans, 87(C3), 2045-2056.

Balistrieri, L., P. G. Brewer, and J. W. Murray (1981), Scavenging residence times of trace metals and surface chemistry of sinking particles in the deep ocean, Deep Sea Res. A, 28(2), 101-121.

Bhat, S. G., S. Krishnaswami, D. Lal, and W. S. Moore (1969), ${ }^{234}$ Th and ${ }^{238}$ U ratios in the ocean, Earth Planet. Sci. Lett., 5, 483-491.

Biscaye, P. E., R. F. Anderson, and B. L. Deck (1988), Fluxes of particles and constituents to the eastern United States continental slope and rise: SEEP-I, Cont. Shelf Res., 8(5-7), 855-904.

Bishop, J. K., P. J. Lam, and T. J. Wood (2012), Getting good particles: Accurate sampling of particles by large volume in-situ filtration, Limnol. Oceanogr. Methods, 10(9), 681-710.

Borggaard, O. K. (1983), Iron oxides in relation to aggregation of soil particles, Acta Agriculturae Scandinavica, 33(3), 257-260.

Buesseler, K. O., M. P. Bacon, J. K. Cochran, and H. D. Livingston (1992), Carbon and nitrogen export during the JGOFS North Atlantic Bloom Experiment estimated from ${ }^{234}{ }^{\mathrm{Th}}:{ }^{238} \mathrm{U}$ disequilibria, Deep Sea Res. A, 39(7-8), 1115-1137. 
Buesseler, K. O., C. R. Benitez-Nelson, S. B. Moran, A. Burd, M. A. Charette, J. K. Cochran, L. Coppola, N. S. Fisher, S. W. Fowler, W. D. Gardner, L. D. Guo, O. Gustafsson, C. Lamborg, P. Masqué, J. C. Miquel, U. Passow, P. H. Santschi, N. Savoye, G. Stewart, and T. Trull (2006), An assessment of particulate organic carbon to thorium-234 ratios in the ocean and their impact on the application of ${ }^{234} \mathrm{Th}$ as a POC flux proxy, Mar. Chem., 100(3), 213-233.

Burd, A. B., S. B. Moran, and G. A. Jackson (2000), A coupled adsorption aggregation model of the POC/ ${ }^{234}$ Th ratio of marine particles., Deep Sea Res. Part I Oceanogr. Res. Pap., 47(1), $103-120$.

Burke, A., O. Marchal, L. I. Bradtmiller, J. F. McManus, and R. François (2011), Application of an inverse method to interpret ${ }^{231} \mathrm{~Pa} /{ }^{230} \mathrm{Th}$ observations from marine sediments, Paleoceanography, 26(1), 1-17.

Charette, M. A., W. S. Moore, P. J. Morris, and P. B. Henderson (2014), Gt10$11 \mathrm{Ra}$ and $\mathrm{Th}$, Biological and chemical oceanography data system, BCO DMO, WHOI, http://data.bco-dmo.org/jg/info/BCO/GEOTRACES/ NorthAtlanticTransect/Ra_Th_GT10\%7Bdir=data.bco-dmo.org/jg/ dir/BCO/GEOTRACES/NorthAtlanticTransect/, data=data.bco-dmo.org: 80 / jg/serv/RESTRICTED/GEOTRACES /NorthAt lanticTransect/Ra_Th_ GT10_joined.html0\%7D?, accessed: 5 April, 2014.

Charette, M. A., P. J. Morris, P. B. Henderson, and W. S. Moore (2015), Radium isotope Distributions during the U.S. GEOTRACES North Atlantic cruises, Mar. Chem., 177, 184-195.

Chase, Z., R. F. Anderson, M. Q. Fleisher, and P. W. Kubik (2002), The influence of particle composition and particle flux on scavenging of $\mathrm{Th}, \mathrm{Pa}$ and $\mathrm{Be}$ in the ocean, Earth Planet. Sci. Lett., 204(1), 215-229.

Choppin, G. R., and P. J. Wong (1998), The chemistry of actinide behavior in marine systems, Aquat. Geochem., 4(1), 77-101. 
Chuang, C. Y., P. H. Santschi, Y. F. Ho, M. H. Conte, L. Guo, D. Schumann, M. Aryanov, and Y. H. $\mathrm{Li}$ (2013), Role of biopolymers as major carrier phases of $\mathrm{Th}, \mathrm{Pa}, \mathrm{Pb}, \mathrm{Po}$, and $\mathrm{Be}$ radionuclides in settling particles from the Atlantic Ocean, Mar. Chem., 157, 131-143.

Clegg, S. L., and J. L. Sarmiento (1989), The hydrolytic scavenging of metal ions by marine particulate matter, Prog. Oceanogr., 23(1), 1-21.

Clegg, S. L., and M. Whitfield (1993), Application of a generalized scavenging model to time series ${ }^{234}$ Th and particle data obtained during the JGOFS North Atlantic Bloom Experiment, Deep Sea Res. Part I Oceanogr. Res. Pap., 40(8), 1529-1545.

Clegg, S. L., M. P. Bacon, and M. Whitfield (1991a), A generalized model for the scavenging of trace metals in the open ocean-II. Thorium scavenging, Deep Sea Res. A, 38(1), 91-120.

Clegg, S. L., M. P. Bacon, and M. Whitfield (1991b), Application of a generalized scavenging model to thorium isotope and particle data at equatorial and high-latitude sites in the Pacific Ocean, J. Geophys. Res. Oceans, 962(C11), 20,655-20,670.

Coale, K. H., and K. W. Bruland (1987), Oceanic stratified euphotic zone as elucidated by ${ }^{234}$ Th: ${ }^{238}$ U disequilibria, Limnol. Oceanogr., 32(1), 189-200.

Collins, J. R., B. R. Edwards, K. Thamatrakoln, J. E. Ossolinski, G. R. DiTullio, K. D. Bidle, S. C. Doney, and B. A. Van Mooy (2015), The multiple fates of sinking particles in the North Atlantic Ocean, Global Biogeochem. Cycles, 29(9), 1471-1494.

Davis, J. A. (1982), Adsorption of natural dissolved organic matter at the oxide/water interface, Geochim. Cosmochim. Acta, 46(11), 2381-2393.

Dixit, S., P. Van Capellen, and A. J. van Bennekom (2001), Processes controlling solubility of biogenic silica and pore water build-up of silicic acid in marine sediments, Mar. Chem., 73(3-4), $333-352$. 
François, R., M. Frank, M. M. Rutgers van der Loeff, and M. P. Bacon (2004), ${ }^{230}$ Th normalization: An essential tool for interpreting sedimentary fluxes during the late Quaternary, Paleoceanography, 19(1).

Geibert, W., and R. Usbeck (2004), Adsorption of thorium and protactinium onto different particle types: experimental findings, Geochim. Cosmochim. Acta, 68(7), 1489-1501.

Greene, W. H. (2012), Econometric Analysis, Pearson Education, Essex, UK.

Grömping, U. (2007), Estimators of relative importance in linear regression based on variance decomposition, Am. Stat., 61(2), 139-147.

Guo, L., C. C. Hung, P. H. Santschi, and I. D. Walsh (2002), ${ }^{234}$ Th scavenging and its relationship to acid polysaccharide abundance in the Gulf of Mexico, Mar. Chem., 78(2), 103-119.

Hayes, C. T., R. F. Anderson, M. Q. Fleisher, S. W. Vivancos, P. J. Lam, D. C. Ohnemus, K. F. Huang, L. F. Robinson, Y. Lu, H. Cheng, R. L. Edwards, and B. S. Moran (2015a), Intensity of Th and Pa scavenging partitioned by particle chemistry in the North Atlantic Ocean, Mar. Chem., 170, 49-60.

Hayes, C. T., R. F. Anderson, M. Q. Fleisher, K. F. Huang, L. F. Robinson, Y. Lu, H. Cheng, L. R. Edwards, and B. S. Moran (2015b), ${ }^{230} \mathrm{Th}$ and ${ }^{231} \mathrm{~Pa}$ on GEOTRACES GA03, the U.S. GEOTRACES North Atlantic transect, and implications for modern and paleoceanographic chemical fluxes, Deep Sea Res. Part II Top. Stud. Oceanogr., 116, 29-41.

Hedges, J. I., G. Eglinton, P. G. Hatcher, D. L. Kirchman, C. Arnosti, S. Derenne, R. P. Evershed, I. Kögel-Knabner, J. W. de Leeuw, R. Littke, W. Michaelis, and J. Rullkötter (2000), The molecularly-uncharacterized component of nonliving organic matter in natural environments, Organ. Geochem., 31(10), 945-958.

Henderson, G. M., and R. F. Anderson (2003), The U-series toolbox for paleoceanography, Reviews in Mineralogy and Geochemistry, 52(1), 493-531. 
Hiemstra, T., and W. H. Van Riemsdijk (2009), A surface structural model for ferrihydrite I: Sites related to primary charge, molar mass, and mass density, Geochim. Cosmochim. Acta, 73(15), 4423-4436.

Honeyman, B. D., and P. H. Santschi (1989), A Brownian-pumping model for oceanic trace metal scavenging: evidence from Th isotopes, J. Mar. Res., 47(4), 951-992.

Honeyman, B. D., L. S. Balistrieri, and J. W. Murray (1988), Oceanic trace metal scavenging: the importance of particle concentration, Deep Sea Res. A, 35(2), 227-246.

Hunter, K. A., and P. S. I. Liss (1979), The surface charge of suspended particles in estuarine and coastal waters, Nature, 282(5741), 823-825.

Jenkins, W. J., W. M. Smethie, and E. A. Boyle (2015), Water mass analysis for the U.S. GEOTRACES North Atlantic Sections, Deep Sea Res. Part II Top. Stud. Oceanogr., 116, 6-20.

Keir, R. S. (1990), The dissolution kinetics of biogenic calcium carbonates in seawater, Geochimi. Cosmochim. Acta, 44(2), 241-252.

Keith, T. Z. (2014), Multiple regression and beyond: An introduction to multiple regression and structural equation modeling, Routledge, New York.

Kruskal, W. (1987), Relative importance by averaging over orderings, Am. Stat., 41(1), 6-10.

Kumar, N., R. Gwiazda, R. Anderson, and P. Froelich $(1993),{ }^{231} \mathrm{~Pa} /{ }^{230} \mathrm{Th}$ ratios in sediments as a proxy for past changes in Southern Ocean productivity, Nature, 362(6415), 45-48.

Lam, P. J., D. C. Ohnemus, and M. E. Auro (2015), Size-fractionated major particle composition and concentrations from the U.S. GEOTRACES North Atlantic Zonal Transect, Deep-Sea Research II, 116, 303-320.

Lerner, P., O. Marchal, P. J. Lam, K. Buesseler, and M. Charette (2017), Kinetics of thorium and particle cycling along the US GEOTRACES North Atlantic Transect, Deep Sea Res. Part I Oceanogr. Res. Pap., 25, 106-128. 
Li, Y. (2005), Controversy over the relationship between major components of sediment-trap materials and the bulk distribution coefficients of ${ }^{230} \mathrm{Th},{ }^{231} \mathrm{~Pa}$, and ${ }^{10} \mathrm{Be}$, Earth Planet. Sci. Lett., 233(1), 1-7.

Lin, P., L. Guo, and M. Chen (2014), Adsorption and fractionation of thorium and protactinium on nanoparticles in seawater, Mar. Chem., 162, 50-59.

Lutz, M., R. Dunbar, and K. Caldeira (2002), Regional variability in the vertical flux of particulate organic carbon in the ocean interior, Global Biogeochem. Cycles, 16(3), 1-18.

Madansky, A. (1988), Linear Regression Analysis, Second Edition., Springer-Verlag, New York, NY.

Moon, E. M., and C. L. Peacock (2013), Modelling Cu (II) adsorption to ferrihydrite and ferrihydrite-bacteria composites: deviation from additive adsorption in the composite sorption system, Geochim. Cosmochim. Acta, 104, 148-164.

Morel, F., and P. Gschwend (1987), Aquatic Surface Chemistry: Chemical Processes at the Particle-Water Interface, John Wiley and Sons, New York.

Morse, J. W. (1986), The surface chemistry of calcium carbonate minerals in natural waters: An overview, Marine Chemistry, 20(1), 91-112.

Niehof, R., and G. I. Loeb (1972), The surface charge of particulate matter in seawater, Limn. Oceanogr., 17, 7-16.

Nozaki, Y., Y. Horibe, and H. Tsubota (1981), The water column distributions of thorium isotopes in the western North Pacific, Earth Planet. Sci. Lett., 54(2), 203-216.

Owens, S. A., S. Pike, and K. O. Buesseler (2015), Thorium-234 as a tracer of particle dynamics and upper ocean export in the Atlantic Ocean, Deep Sea Research II, 116, 42-59.

Peacock, C. L., and D. M. Sherman (2007), Sorption of Ni by birnessite: Equilibrium controls on Ni in seawater, Geochim. Cosmochim. Acta, 238(1-2), 94-106. 
Quigley, M. S., P. H. Santschi, L. Guo, and B. D. Honeyman (2001), Sorption irreversibility and coagulation behavior of ${ }^{234} \mathrm{Th}$ with marine organic matter, Mar. Chem., 76(1), 27-45.

Quigley, M. S., P. H. Santschi, C. C. Hung, L. Guo, and B. D. Honeyman (2002), Importance of acid polysaccharides for ${ }^{234} \mathrm{Th}$ complexation to marine organic matter, Limnol. Oceanogr., 47(2), 367-377.

Quiroz, N. G. A., C. C. Hung, and P. H. Santschi (2006), Binding of thorium (IV) to carboxylate, phosphate and sulfate functional groups from marine exopolymeric substances (EPS), Mar. Chem., 100(3), 337-353.

Rencher, A. C. (1998), Multivariate Statistical Inference and Applications, John Wiley and Sons, New York, NY.

Roberts, K. A., C. Xu, C. C. Hung, M. H. Conte, and P. H. Santschi (2009), Scavenging and fractionation of thorium vs. protactinium in the ocean, as determined from particle-water partitioning experiments with sediment trap material from the Gulf of Mexico and Sargasso Sea, Earth Planet. Sci. Lett., 286(1), 131-138.

Roy-Barman, M., C. Jeandel, M. Souhaut, M. M. van der Loeff, I. Voege, N. Leblond, and R. Freydier (2005), The influence of particle composition on thorium scavenging in the NE Atlantic ocean (POMME experiment), Earth Planet. Sci. Lett., 240(3), 681-693.

Santschi, P. H., C. C. Hung, G. Schultz, N. Alvarado-Quiroz, L. Guo, J. Pinckney, and I. Walsh (2003), Control of acid polysaccharide production and ${ }^{234} \mathrm{Th}$ and POC export fluxes by marine organisms, Geophys. Res. Lett., 30(2), 47-64.

Santschi, P. H., J. W. Murray, M. Baskaran, C. R. Benitez-Nelosn, L. D. Guo, C. C. Hung, C. Lamborg, S. B. Moran, U. Passow, and M. Roy-Barman (2006), Thorium speciation in seawater, Mar. Chem., 100(3), 250-268. 
Scholten, J. C., J. Fietzke, S. Vogler, M. M. Rutgers van der Loeff, A. Mangini, W. Koeve, J. Waniek, P. Stoffers, A. Antia, and J. Kuss (2001), Trapping efficiencies of sediment traps from the deep Eastern North Atlantic: the ${ }^{230}$ Th calibration, Deep Sea Res. Part II Top. Stud. Oceanogr., 48(10), 2383-2408.

Scholten, J. C., J. Fietzke, A. Mangini, P. Stoffers, T. Rixen, B. Gaye-Haake, T. Blanz, V. Ramaswamy, F. Sirocko, H. Schulz, and V. Ittekkot (2005), Radionuclide fluxes in the Arabian Sea: the role of particle composition, Earth Planet. Sci. Lett., 230(3-4), 319-337.

Seber, G. A. F., and A. J. Lee (1992), Linear Regression Analysis, Second Edition, John Wiley and Sons, Inc, Hoboken, NJ.

Shelley, R. U., P. L. Morton, and W. M. Landing (2015), Elemental ratios and enrichment factors in aerosols from the US-GEOTRACES North Atlantic transects, Deep Sea Research Part II: Topical Studies in Oceanography, 116, 262-272.

Sheridan, C. C., C. Lee, S. G. Wakeham, and J. K. B. Bishop (2002), Suspended particle organic composition and cycling in surface and midwaters of the equatorial Pacific Ocean, Deep Sea Res. Part I Oceanogr. Res. Pap., 49(11), 1983-2008.

Stumm, W., and J. Morgan (1996), Aquatic Chemistry, 3rd ed., John Wiley and Sons, New York.

Tarantola, A., and B. Valette (1982), Generalized nonlinear inverse problems solved using the least squares criterion, Rev. Geophys., 20(2), 219-232.

Taylor, S. R., and S. M. McLennan (1995), The geochemical evolution of the continental crust, Rev. Geophys., 33(2), 241-265.

Toner, B., S. Fakra, M. Villalobos, T. Warwick, and G. Sposito (2005), Spatially resolved characterization of biogenic manganese oxide production within a bacterial biofilm, Applied and environmental microbiology, 71(3), 1300-1310. 
Wakeham, S. G., C. Lee, J. I. Hedges, P. J. Hernes, and M. J. Peterson (1997), Molecular indicators of diagenetic status in marine organic matter, Geochim. Cosmochim. Acta, 61(24), 5563-5369.

Yu, E.-F., R. François, and M. P. Bacon (1996), Similar rates of modern and last-glacial ocean thermohaline circulation inferred from radiochemical data, Nature, 379, 689-694. 
Figure 1: Stations occupied by the R/V Knorr during the GEOTRACES North Atlantic section (GA03). The grey dots show the stations occupied during the first leg (October 2010) and the black dots show the stations occupied during the second leg (November-December 2011). The open circle is both station GT10-12 of the first leg and station GT11-24 of the second leg. The data analyzed in this paper occur at stations marked by red asterisks. The solid lines show the coastline (black) and the 3000-m isobath (grey).

Figure 2: Pearson correlation coefficients between pairs of particle phases at selected stations of GA03. (a) Correlations between POC, PIC, bSi, lithogenic material, Mn (oxyhydr)oxides, and Fe (oxyhydr)oxides. (b) Correlations between the sum of biogenic particles (POC+PIC+bSi), lithogenic material, Mn (oxyhydr)oxides, and $\mathrm{Fe}$ (oxyhydr)oxides.

Figure 3: Principal component coefficients for each particle phase, with the percentage of total particle variance captured put into parentheses. The left panel corresponds to $\mathrm{PC} 1$, and the right panel corresponds to $\mathrm{PC} 2$. In each panel, the black (grey) bars show results obtained from the covariance (correlation) matrix.

Figure 4: Section plots of the principal components. Left (right) panels show the PCs calculated from the covariance (correlation) matrix. Note that the third and fourth stations from the right of each panel (GT10-12 and GT11-24, respectively) are actually at the same geographic location $\left(17^{\circ} 23^{\prime} \mathrm{N}, 24^{\circ} 30^{\prime} \mathrm{W}\right)$.

Figure 5: Estimates of the adsorption rate constant, $k_{1}\left(\mathrm{yr}^{-1}\right)$, at selected stations of the US GEOTRACES North Atlantic section. The third and fourth stations from the right of each panel (GT10-12 and GT11-24, respectively) are actually at the same geographic location $\left(17^{\circ} 23^{\prime} \mathrm{N}, 24^{\circ} 30^{\prime} \mathrm{W}\right)$. The largest value inferred for $k_{1}\left(21 \mathrm{yr}^{-1}\right.$ at $3200 \mathrm{~m}$ at station GT11-16) is not shown so that individual values of $k_{1}$ are more easily distinguished.

Figure 6: Regressions performed using OLS. Panels (a), (b), and (c) correspond to the regression for all stations, stations west of GT11-24, and stations east of and including GT11-24, respectively. Panels (d-f) correspond, respectively, to the same groups of stations and panels (a-c), but for the regression of $\ln \left(k_{1}\right)$ vs the natural logarithm of the particle composition data. The solid line is the best fit, and the error bars are \pm 1 standard deviation

Figure 7: Relative Importance $(R I)$ of particle phases for model I (upper panels) and model II (lower panels). Panels (a,d), (b,e), and (c,f) correspond to all stations, western stations, and eastern stations, respectively. The black and grey bars are the $R I$ values obtained by respectively, dominance analysis and averaging over orders.

Figure 8: Panels a, b, and c show $k_{1}$ obtained from inversion of radiochemical data vs. $k_{1}$ obtained from regression against particle composition data using the ATI. Panels $\mathrm{d}$, e, and $\mathrm{f}$ are similar to panels $\mathrm{a}, \mathrm{b}$, and $\mathrm{c}$, except show $\ln \left(k_{1}\right)$ rather than $k_{1}$. Panels $(\mathrm{a}, \mathrm{d}),(\mathrm{b}, \mathrm{e})$, and $(\mathrm{c}, \mathrm{f})$ correspond to the regression for all stations, stations west of GT11-24, and stations east of and including GT11-24, respectively. The solid line is the best fit, and the error bars are \pm 1 standard deviation.

Figure 9: Regressions of $\ln \left(k_{1}\right)$ estimated by inversion against the natural logarithm of measured bulk particle concentration at (a) all selected stations, (b) stations west of GT11-24, and (c) stations east of and including GT11-24. The solid line is the best fit and error bars are \pm 1 standard deviation. 
Figure A1: $k_{1}$ obtained from an inversion with bulk particle concentration data vs. $k_{1}$ obtained from an inversion without bulk particle concentration data. The error bars are \pm 2 standard deviations. The solid line is the OLS fit, while the dashed line is the line of perfect agreement. 


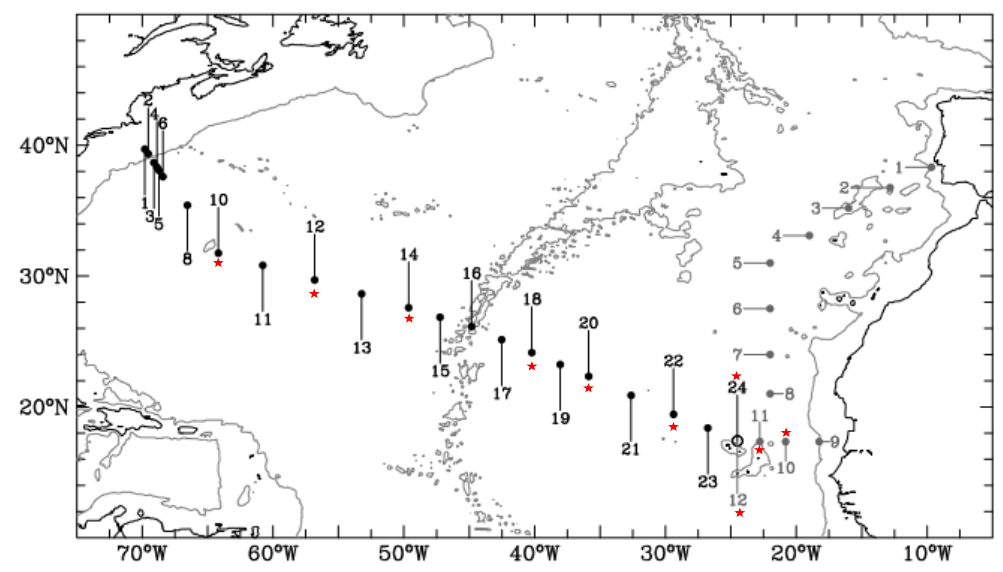



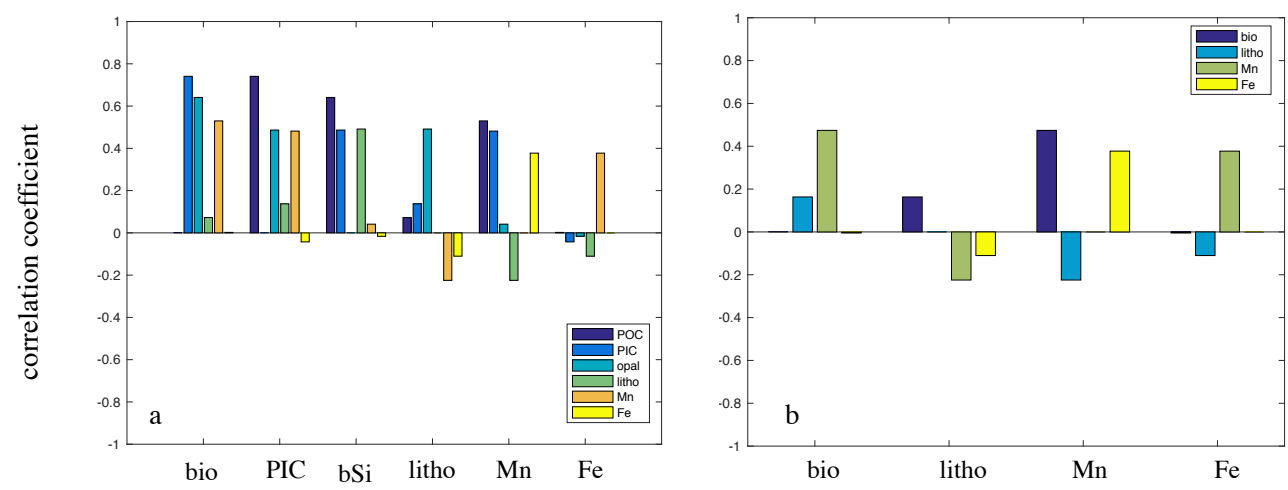

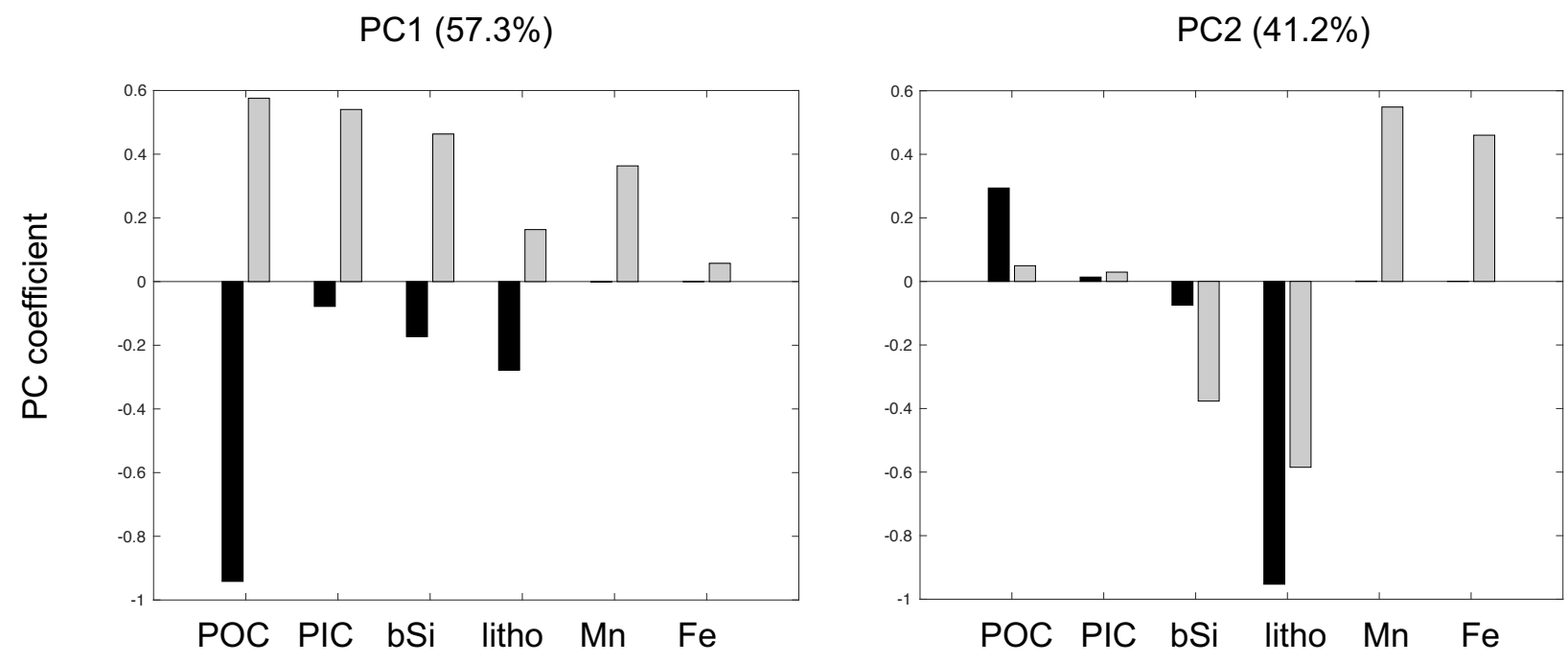

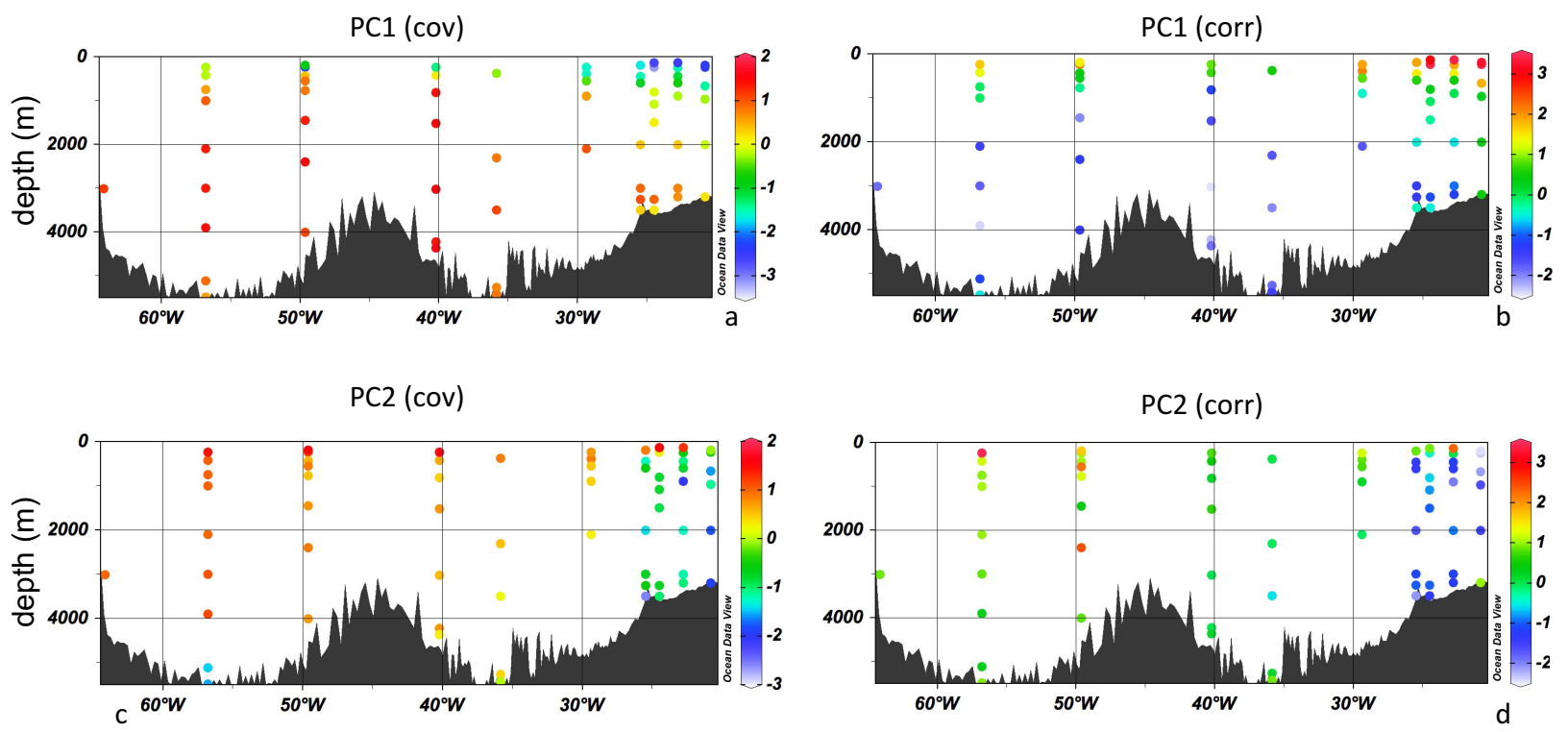


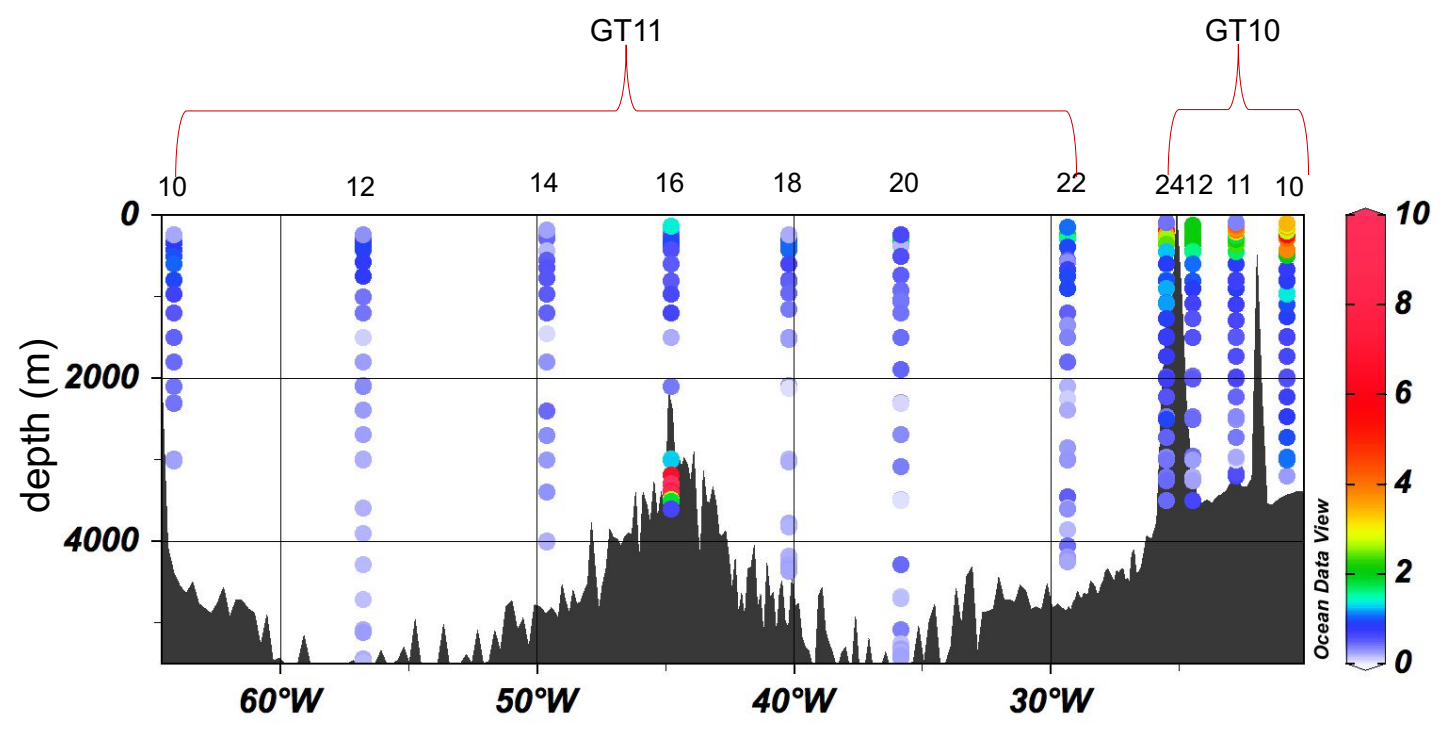



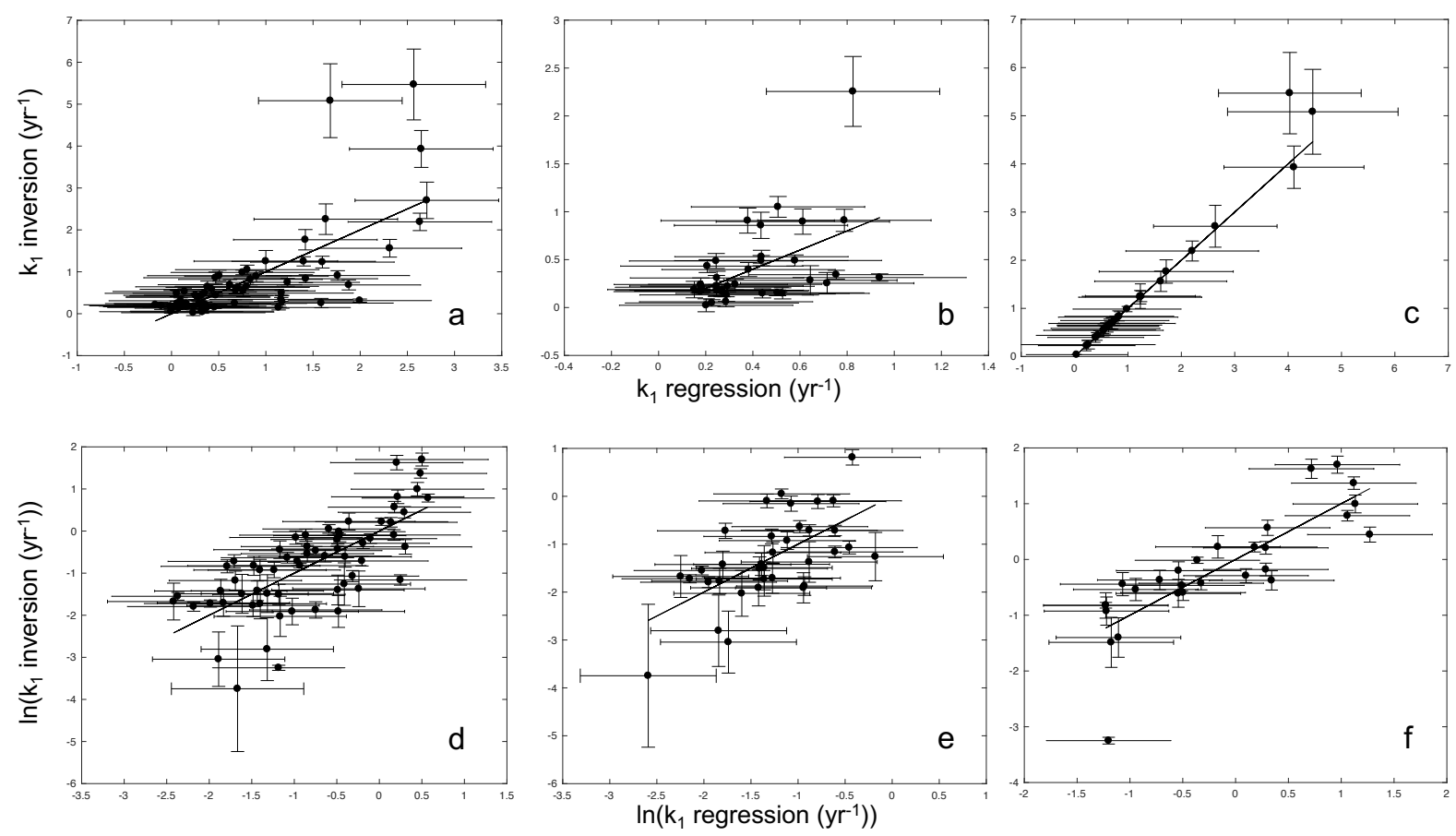

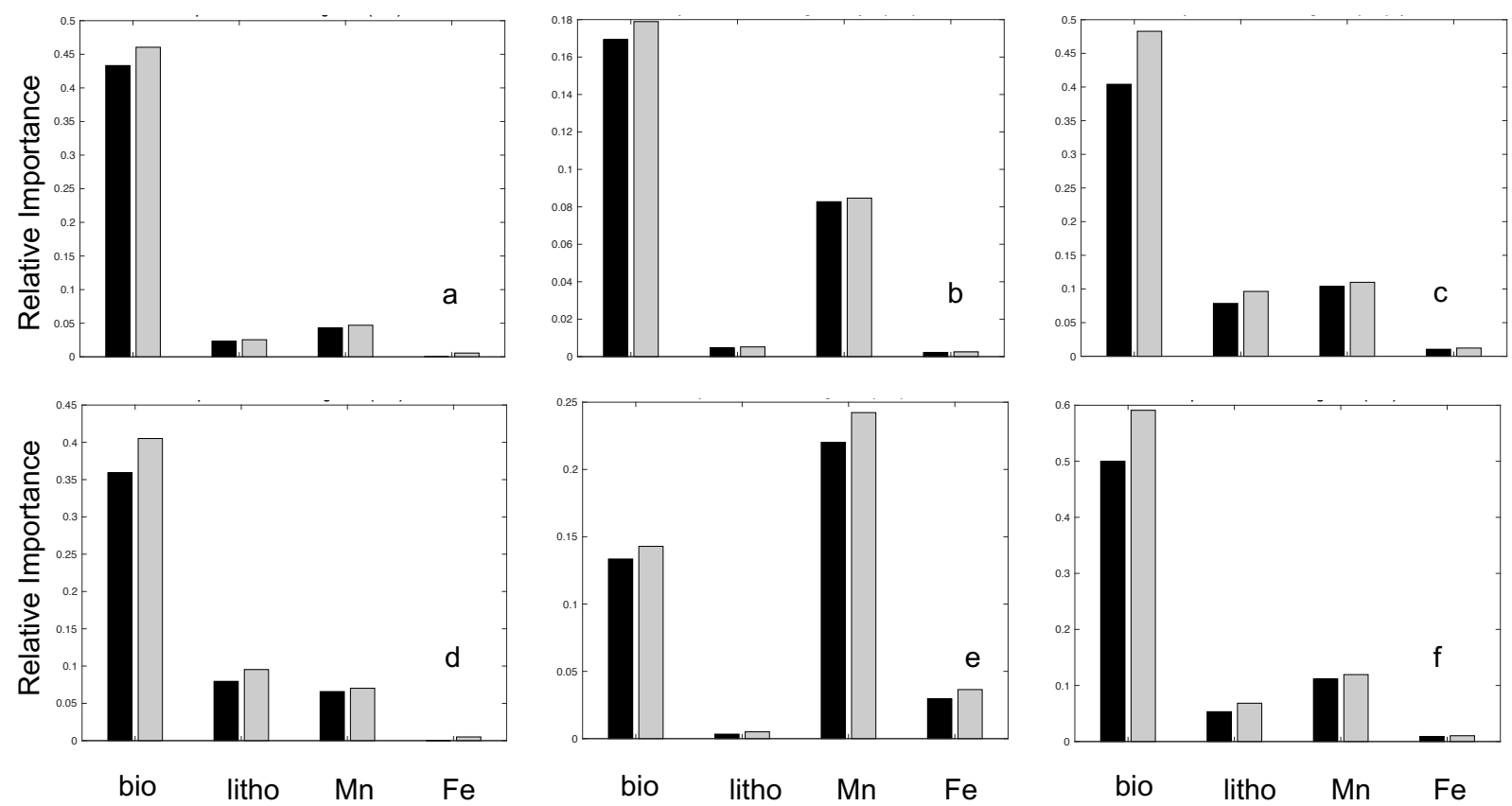

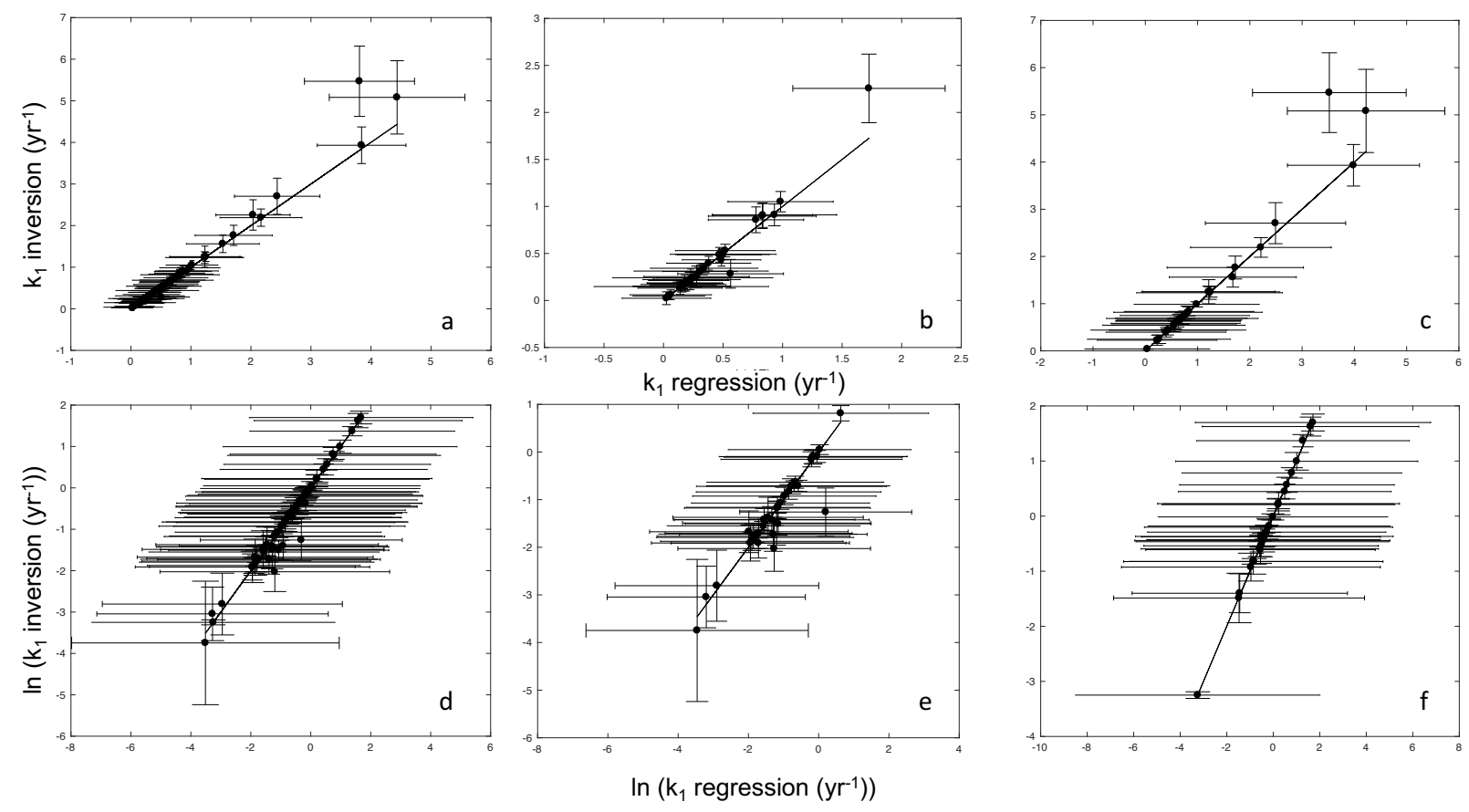

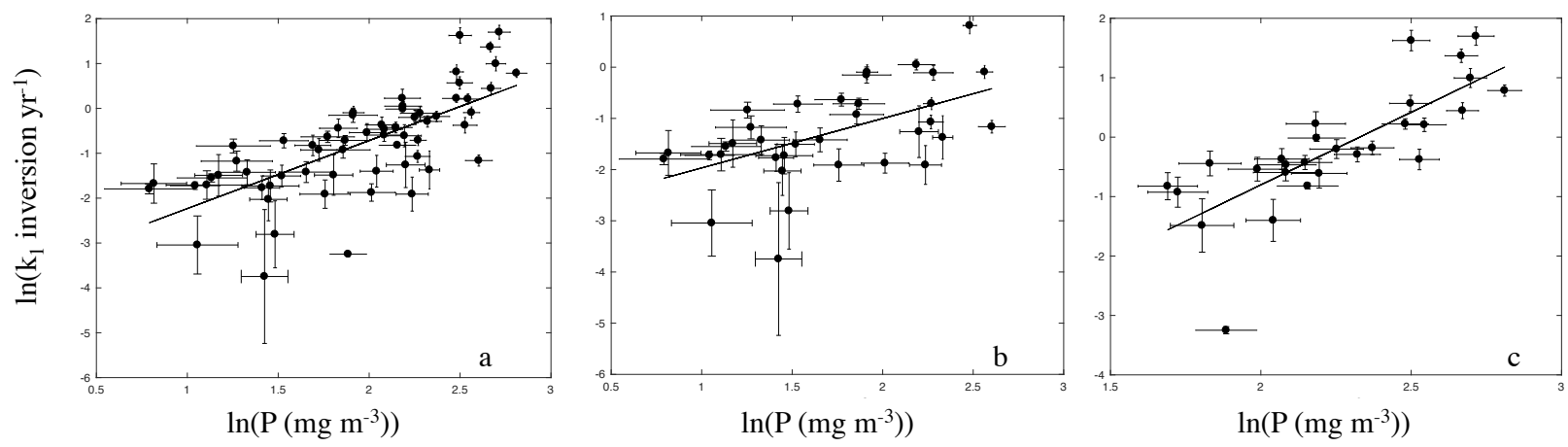


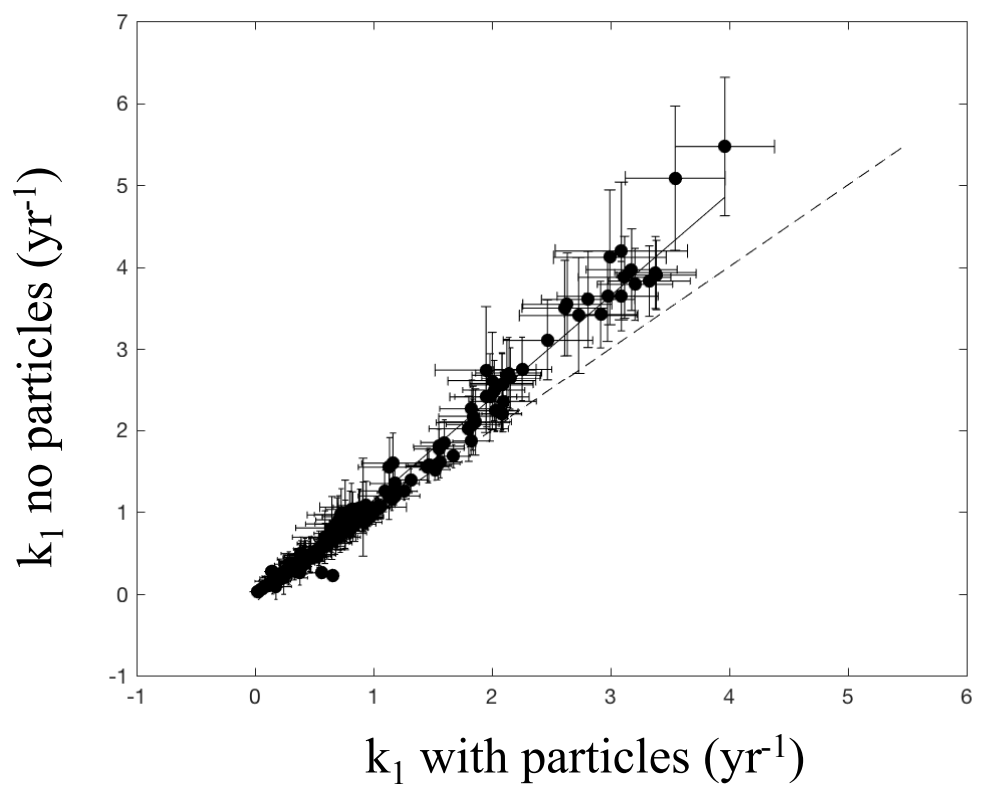


In this supplement, we present (i) a figure showing the relationship between $K_{D}$ and particle 2 phase data from previous studies (see second paragraph of the Introduction in the main text) and 3 (ii) the equivalents of tables 2-5 in the main text with the regression coefficients $\left(a_{0}, b_{0}\right)$ added and 4 the columns labeled as $a_{0}, a_{1}, a_{2}, a_{3}, a_{4}$.
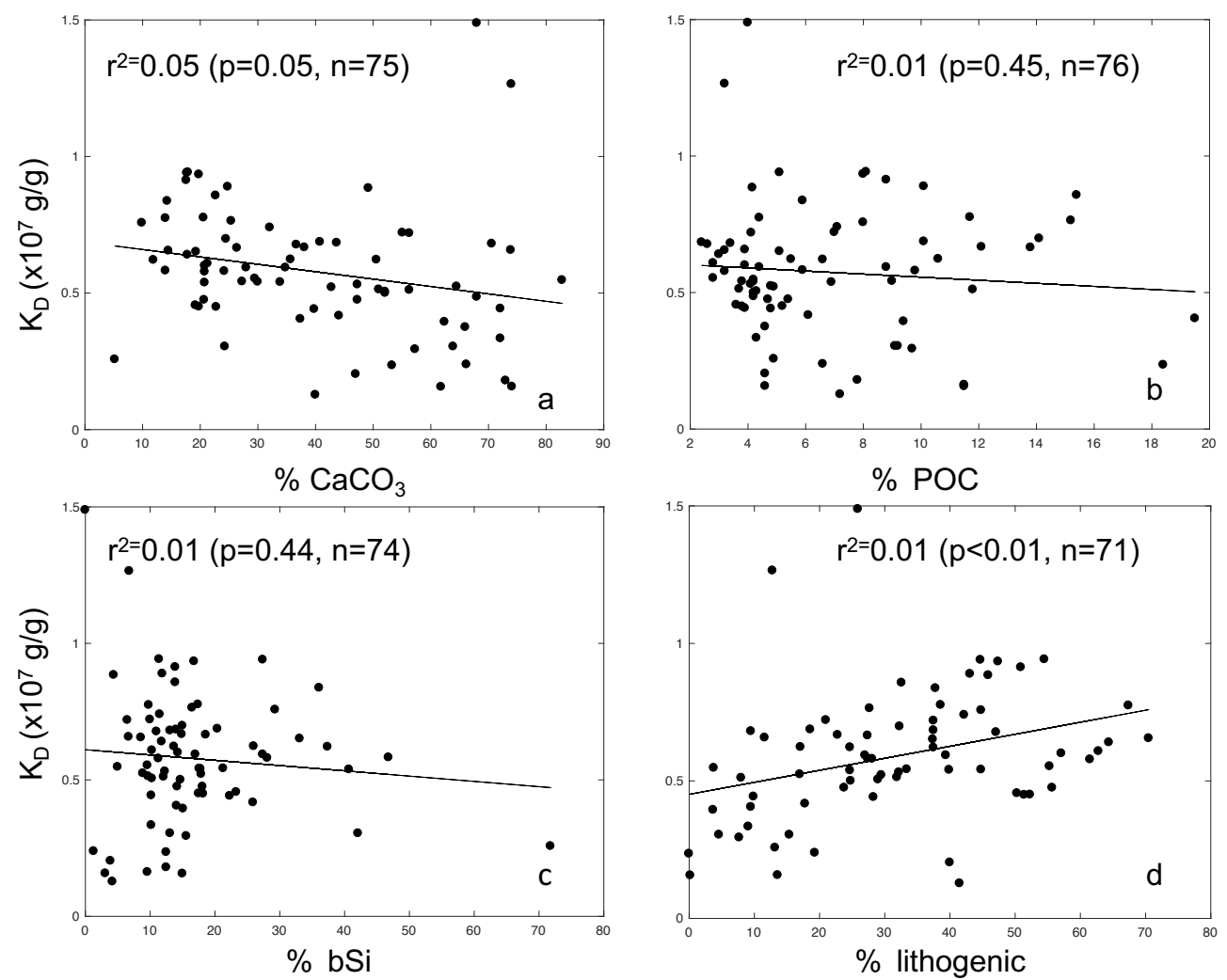

Figure S1: Variations of $K_{D}$ with $\% \mathrm{CaCO}_{3}$ (a), \% organic carbon (b), \% biogenic silica (c), and $\%$ lithogenic material $(\mathrm{d})$.

Table S1: Regression coefficients \pm 1 standard error for model I ( $a_{0}$ in $\mathrm{yr}^{-1}$, and all other coefficients in $\left.\mathrm{yr}^{-1} \mathrm{~m}^{3} \mathrm{mg}^{-1}\right)$

\begin{tabular}{|l|c|c|c|c|c|}
\hline & $a_{0}$ & $a_{1}$ & $a_{2}$ & $a_{3}$ & $a_{4}$ \\
\hline all stations (n=63) & $-0.26 \pm 0.35(0.46)$ & $0.52 \pm 0.08(<0.01)^{a}$ & $0.05 \pm 0.10(0.65)$ & $-44.62 \pm 49.11(0.36)$ & $14.56 \pm 18.01(0.42)$ \\
\hline western stations (n=35) & $0.14 \pm 0.21(0.89)$ & $0.14 \pm 0.07(0.06)$ & $0.03 \pm 0.10(0.76)$ & $21.24 \pm 34.92(0.54)$ & $-1.24 \pm 11.82(0.92)$ \\
\hline eastern stations (n=28) & $0.52 \pm 1.15(0.65)$ & $0.58 \pm 0.15(<0.01)$ & $-0.31 \pm 0.29(0.29)$ & $-3.31 \pm 107.94(0.98)$ & $10.38 \pm 36.21(0.77)$ \\
\hline
\end{tabular}

a. Values in parentheses are $p$-values.

Table S2: Regression coefficients \pm 1 standard error for model II $\left(a_{0}\right.$ in $\left.\ln \left(\mathrm{m}^{3} \mathrm{~g}^{-1} \mathrm{yr}^{-1}\right)\right)$

\begin{tabular}{|l|c|c|c|c|c|}
\hline & $a_{0}$ & $a_{1}$ & $a_{2}$ & $a_{3}$ & $a_{4}$ \\
\hline all stations (n=63) & $-0.81 \pm 1.56(0.61)$ & $1.03 \pm 0.20(<0.01)^{a}$ & $0.35 \pm 0.20(0.08)$ & $0.13 \pm 0.31(0.68)$ & $0.01 \pm 0.03(0.61)$ \\
\hline western stations (n=35) & $3.55 \pm 2.16(0.11)$ & $0.32 \pm 0.27(0.22)$ & $-0.17 \pm 0.31(0.58)$ & $0.92 \pm 0.42(0.03)$ & $0.03 \pm 0.03(0.35)$ \\
\hline eastern stations $(\mathrm{n}=28)$ & $-2.15 \pm 2.15(0.32)$ & $1.45 \pm 0.29(<0.01)$ & $-0.46 \pm 0.47(0.32)$ & $-0.20 \pm 0.41(0.62)$ & $-0.01 \pm 0.04(0.86)$ \\
\hline
\end{tabular}

$a$. Values in parentheses are $p$-values. 
Table S3: Regression coefficients \pm 1 standard deviation for model I (ATI; $a_{0}$ is in $\mathrm{yr}^{-1}$, and all other coefficients are in $\mathrm{yr}^{-1} \mathrm{~m}^{3} \mathrm{mg}^{-1}$ )

\begin{tabular}{|l|c|c|c|c|c|}
\hline & $a_{0}$ & $a_{1}$ & $a_{2}$ & $a_{3}$ & $a_{4}$ \\
\hline all stations (n=63) & $-0.62 \pm 0.23$ & $0.35 \pm 0.07$ & $0.25 \pm 0.11$ & $-38.5 \pm 20.8$ & $103.5 \pm 14.4$ \\
\hline western stations (n=35) & $-0.25 \pm 0.22$ & $0.19 \pm 0.07$ & $0.17 \pm 0.16$ & $-27.4 \pm 20.1$ & $73.64 \pm 14.67$ \\
\hline eastern stations (n=28) & $-0.25 \pm 0.9$ & $0.58 \pm 0.24$ & $0.30 \pm 0.58$ & $-182.4 \pm 144.2$ & $176.5 \pm 62.7$ \\
\hline
\end{tabular}

Table S4: Regression coefficients \pm 1 standard deviation for model II (ATI; $a_{0}$ in $\ln \left(\mathrm{m}^{3} \mathrm{~g}^{-1} \mathrm{yr}^{-1}\right)$ )

\begin{tabular}{|l|c|c|c|c|c|}
\hline & $a_{0}$ & $a_{1}$ & $a_{2}$ & $a_{3}$ & $a_{4}$ \\
\hline all stations (n=63) & $-9.29 \pm 2.37$ & $1.81 \pm 0.18$ & $0.16 \pm 0.20$ & $-2.03 \pm 0.53$ & $0.46 \pm 0.09$ \\
\hline western stations $(\mathrm{n}=35)$ & $-1.65 \pm 1.80$ & $1.27 \pm 0.20$ & $-0.37 \pm 0.20$ & $-0.40 \pm 0.38$ & $0.26 \pm 0.06$ \\
\hline eastern station $(\mathrm{n}=28)$ & $6.26 \pm 3.05$ & $1.69 \pm 0.34$ & $-1.09 \pm 0.46$ & $1.03 \pm 0.54$ & $-0.22 \pm 0.06$ \\
\hline
\end{tabular}

